\title{
UNA APROXIMACIÓN CUANTITATIVA AL TRABAJO DESTINADO A LA ARQUITECTURA MONUMENTAL EN LA PREHISTORIA RECIENTE DE LA MESETA NORTE ESPAÑOLA
}

\author{
AN APPROACH TO THE CONSTRUCTION LABOR INVESTED ON THE \\ MONUMENTS OF THE LATE PREHISTORIC NORTHERN MESETA
}

\author{
RODRIGO VILLALOBOS GARCÍA*
}

\begin{abstract}
Resumen: La arquitectura monumental es una característica común a gran parte de las culturas prehistóricas y puede ser utilizada como un indicador apropiado para indagar en el tamaño del poder político responsable de su construcción. A través de la estimación del trabajo dedicado a los monumentos, que puede calcularse mediante la cuantificación de las construcciones identificadas en el registro arqueológico y la aplicación de coeficientes de transformación extraídos de la arqueología experimental o de observaciones etnográficas, se nos presenta una vía para medir esa capacidad de movilización. Con esta estrategia aquí analizamos el trabajo invertido en los monumentos neolíticos y calcolíticos de la Meseta Norte española como son megalitos, asentamientos fortificados y recintos de fosos. Nuestros cálculos nos han permitido identificar dos tendencias: a lo largo del tiempo hemos visto que el trabajo invertido por monumento aumentó exponencialmente y en cuanto al espacio hemos identificado que es en el centro-suroeste de la Meseta Norte donde se erigieron los monumentos en los que se invirtió una mayor cantidad de trabajo. La contextualización de esta variable junto con otros aspectos como demografía, especialización económica o desigualdades sociales nos muestra que este es un valioso indicador a tener en cuenta para la investigación arqueológica de los procesos de transformación cultural.
\end{abstract}

Palabras Clave: Trabajo colectivo; Arquitectura monumental; Neolítico; Calcolítico; Meseta Norte Española.

* Departamento de Prehistoria, Arqueología, Antropología Social y CC. y TT. Historiográficas (Universidad de Valladolid). Facultad

\begin{abstract}
Most of the prehistoric cultures share the characteristic of having produced monumental architecture, which is a good indicator of the size of the polity responsible of its construction. The measurement of monuments' size and volumes could be used to estimate the quantity of work invested by using coefficients deduced from experimental archaeology or ethnographic observations. This is thought to be an appropriate way to calculate the political power behind labor mobilization. In this paper this strategy is applied to monuments of the Late Prehistoric Spanish Northern Meseta such as megalithic buildings, walled settlements and causewayed enclosures. The results offer two patterns. The work invested on monuments grew exponentially from the Early Neolithic to the Copper Age, and there were more work invested per monument on the central and southwestern Northern Meseta than on the northeastern part. The variable of work invested contextualized with other issues such as demography, economic specialization or social inequalities could be a good indicator to count for the archaeology of cultural transformation processes.
\end{abstract}

Keywords: Collective labor; Monumental architecture; Neolithic, Copper Age, Spanish Northern Meseta.

de Filosofía y Letras, Pz/ del Campus s/n 47011 Valladolid, España. Correo-e: rodrigovillalobosgarcia@gmail.com 


\section{INTRODUCCIÓN}

La arquitectura monumental ha sido el exponente más representativo de las culturas prehistóricas desde que tanto en el Viejo como en el Nuevo Mundo comenzaron a identificarse megalitos, complejos ceremoniales, recintos fosados, etc. y, ya en los primeros momentos en los que se planteó que la arqueología podría ser capaz de indagar en cuestiones como la organización social pretérita, estas construcciones empezaron a ser concebidas como indicadores de un poder político fuerte. Así, al explicar sus diez criterios para reconocer una cultura que ha superado la revolución urbana y que, por tanto, se habría constituido como sociedad civilizada, Childe apuntó la relevancia de los monumentos al conjeturar que «truly monumental public buildings [...] symbolize the concentration of social surplus» (Childe 1950: 12). Es posible afirmar que el empleo de la monumentalidad arquitectónica como símbolo de poder es una práctica universal (Trigger 1990), y son varios los autores que han optado por desarrollar el aspecto cuantitativo de este hecho cultural al postular que la cantidad de energía o trabajo destinados a un monumento serían representativos de la capacidad de control del excedente y de la población por parte de los líderes políticos (Renfrew 1973, Kolb 1997, Peterson y Drennan 2012). Dado que a partir del registro arqueológico es posible medir el volumen de subsuelo excavado, el peso y la distancia del material constructivo acarreado o el tamaño de estructuras construidas, existe la posibilidad de calcular una buena parte del trabajo invertido en la construcción de los complejos monumentales prehistóricos en horas-persona o días-persona.

Estas son unidades de medida empleadas para cuantificar cantidades de trabajo y expresan el trabajo que una persona es capaz de desarrollar en una hora o una jornada, respectivamente. Hasta hace poco tiempo se usaba el término "horas/días-hombre", pero la voluntad de manejar un lenguaje no sexista ha conducido a adoptar el término que nosotros empleamos u otros equiparables como "hora/día-esfuerzo". En todo caso, 1.000 díaspersona mide el trabajo total de una obra que ha podido implicar igualmente a 1 sola persona durante 1.000 jornadas, a una cuadrilla de 10 personas durante 100 jornadas, a una cuadrilla de 100 personas durante 10 jornadas $\mathrm{o}$ a una cuadrilla de 1.000 personas durante 1 jornada.

Por tanto, asumiendo que en cuanto a la arquitectura monumental existe una relación directamente proporcional entre una variable objetiva como es el trabajo $\mathrm{y}$ una dimensión social abstracta como es el poder o el estatus, se abre la puerta a estimar y hacer comparable a través del tiempo y del espacio la capacidad de movilización de distintas unidades políticas.

Uno de los escenarios del Viejo Mundo donde es posible analizar los procesos de aparición de estructuras sociales desiguales y poderes políticos fuertes es la península ibérica de los comienzos de la Prehistoria Reciente (Chapman 2008). En la actualidad, este marco ha visto abrirse el debate sobre la organización del territorio, las transformaciones en la economía subsistencial o la distribución y acumulación de artefactos sociotécni$\cos$, cuestiones que también pueden verse complementadas con el análisis sobre el trabajo invertido en obras monumentales. Dado que el registro arqueológico peninsular es profuso en construcciones como megalitos (Muñoz Carballo 1986, Fernández Eraso y Mújika Alustiza 2010), recintos fosados (Márquez Romero y Jiménez Jáimez 2010) y poblados amurallados (Jorge 1994), consideramos que se muestra apto para la realización de un análisis siguiendo esta estrategia. Aunque la funcionalidad de estas distintas obras es todavía cuestión abierta a debate - ¿tumbas, lugares de culto, centros de agregación social, fortificaciones?- lo cierto es que en todos los casos se habría requerido de la organización de grandes cantidades de trabajo cuya mano de obra excedió en número a la básica unidad familiar.

Hasta la fecha tan solo hay un puñado de estudios que han aplicado este planteamiento a monumentos neolíticos y calcolíticos de distintas regiones peninsulares (e.g. Vázquez Varela et al. 1987: cap. 4, González López y Teijeiro López 1997, Moreno Gallo 2004: 23 24, Bernabeu Aubán et al. 2006: cap. 8.6). En estas páginas vamos a presentar el análisis del trabajo dedicado a los monumentos de la Meseta Norte, una región del interior peninsular que presenta un registro con una sucesión más o menos continua de obras colectivas fechadas entre el VI y el III milenio cal a.C.

\section{LAS CONSTRUCCIONES MONUMENTALES DEL NEOLÍTICO Y CALCOLÍTICO EN LA MESETA NORTE ESPAÑOLA}

Los inicios de la Prehistoria Reciente en la Meseta Norte son un lapso temporal que puede subdividirse en tres etapas que cuentan con una definición cronocultural bastante clara, un Neolítico premegalítico que aquí denominaremos Neolítico Antiguo (c 5300-4200 cal a.C.), un Neolítico megalítico que aquí denominaremos Neolítico Final ( $c$ 4200-3100 cal a.C.) y el Calcolítico (c 3100-2200 cal a.C.) (Delibes de Castro y Fernández 
Manzano 2000, Villalobos García 2014a). El Neolítico Antiguo se corresponde con la irrupción en el territorio normeseteño de la agricultura y la ganadería, actividades que ocuparon a grupos humanos de pequeño tamaño que probablemente practicaron una itinerancia interanual. Con la llegada del Neolítico Final estas mismas comunidades, que continuarían con unos modos de vida similares a los del momento precedente, construyeron estructuras arquitectónicas ortostáticas cubiertas por túmulos. El Calcolítico vio cómo estos grupos humanos crecieron en tamaño y se hicieron sedentarios, desarrollaron una economía más intensificada e integrada y construyeron poblados amurallados y recintos de fosos.

Para el primero de nuestros periodos de estudio solo se conoce un posible caso de obra colectiva, el recinto circular localizado en el asentamiento de La Revilla del Campo (Ambrona, Soria). Este consiste en tres estrechas zanjas realizadas posiblemente para acoger una empalizada y así cerrar un espacio circular de unos 30 $\mathrm{m}$ de diámetro, cuya construcción ha sido datada por radiocarbono a finales del VI milenio cal a.C. (Rojo Guerra et al. 2008b, 2008c: 26).

El Neolítico Final resulta mucho más pródigo a este respecto, pues en la Meseta Norte hay contabilizados aproximadamente dos centenares de yacimientos de este tipo. La mayoría de estos se compone de una estructura ortostática rodeada de un túmulo de tierra y piedras $\mathrm{y}$, aunque principalmente fueron empleados para acoger inhumaciones colectivas, también existen pruebas de su uso para otro tipo de actividades no estrictamente funerarias (Delibes de Castro 2010, Rojo Guerra y Garrido Pena 2012, Villalobos García 2014b). Numerosos trabajos de prospección y excavación han descrito minuciosamente estos monumentos (López Plaza 1982, Delibes de Castro y Santonja Gómez 1986, Palomino Lázaro 1989, 1990, Rojo Guerra 1992, Delibes de Castro et al. 1993, Fabián García 1997, Palomino Lázaro y Rojo Guerra 1997, Estremera Portela y Fabián García 2002, Rojo Guerra et al. 2005, Palomino Lázaro et al. 2006, Moreno Gallo 2009, Pérez Rodríguez 2010, Carmona Ballestero et al. 2014) y, gracias a ellos, sabemos que sus dimensiones medias son de unos $10 \mathrm{~m}$ de diámetro y $1,5 \mathrm{~m}$ de altura, aunque hay casos que llegan a alcanzar los $25 \mathrm{~m}$ de diámetro y $4 \mathrm{~m}$ de altura.

En último lugar, de época calcolítica se conocen dos tipos de construcciones de gran empaque, que son los poblados fortificados y los recintos de fosos. De los primeros solo se han identificado tres ejemplares seguros, El Alto del Quemado (El Álamo, Ávila) (López
Plaza 1994), El Pedroso (San Martín de El Pedroso, Zamora) (Delibes de Castro 1995a, Delibes de Castro et al. 1995) y El Pozuelo (Ambrona, Soria) (Rojo Guerra et al. 2005: 228, 2008a), aunque solo se han publicado descripciones detalladas de los dos primeros. A estos podría añadírseles El Pico de la Mora (Mélida de Peñafiel, Valladolid), un poblado campaniforme localizado en un espigón de páramo y cerrado por una corta muralla que, perfectamente apreciable en fotografía aérea, todavía se encuentra pendiente de confirmar mediante excavación (Rodríguez Marcos y Moral del Hoyo 2007, Rodríguez Marcos 2008). Mientras que El Alto del Quemado es un pequeño recinto de 1500 $\mathrm{m}^{2}$ cerrado por una muralla de $1,5 \mathrm{~m}$ de anchura y la misma altura y un foso de $2 \mathrm{~m}$ de profundidad con 2,22,5 $\mathrm{m}$ de anchura en superficie y 1-1,5 m en la base (López Plaza 1994), el segundo tiene una muralla de $500 \mathrm{~m}$ de longitud y $3 \mathrm{~m}$ de espesor que cuenta, incluso, con algunas torres adosadas (Delibes de Castro 1995a). En cuanto a los recintos de fosos, la fotografía aérea y la teledetección han servido para descubrir y caracterizar una veintena de ellos distribuidos por la cuenca sedimentaria, de los cuales tres -Las Pozas (Casaseca de las Chanas, Zamora), El Casetón de la Era (Villalba de los Alcores, Valladolid) y Santa Cruz III (Cabezón de Pisuerga, Valladolid)- han sido parcialmente excavados. Dichos trabajos han revelado que en estos lugares se excavaron en el subsuelo uno o varios fosos circulares de entre 30 y $200 \mathrm{~m}$ de diámetro con unas dimensiones de entre 3 y $6 \mathrm{~m}$ de anchura en la superficie y entre 0,9 y 2,25 $\mathrm{m}$ de profundidad (Delibes de Castro et al. 2009, 2014, García García 2013).

\section{MÉTODOS Y TÉCNICAS}

\subsection{Consideraciones previas}

Como planteamos en la introducción, nuestra pretensión es utilizar los monumentos prehistóricos normeseteños (fig. 1) para estimar la cantidad de trabajo invertido en ellos y de ahí deducir, teniendo en cuenta las limitaciones de este análisis, la capacidad de los poderes políticos de la Prehistoria Reciente normeseteña para movilizar fuerza de trabajo. Pero antes de nada conviene hacer algunas aclaraciones.

En primer lugar hay que reconocer que el registro arqueológico no nos muestra la entidad total de la obra realizada en su momento. En el caso de los megalitos, existen pruebas que sugieren que las cámaras se hallaban cubiertas por estructuras posiblemente realizadas en 


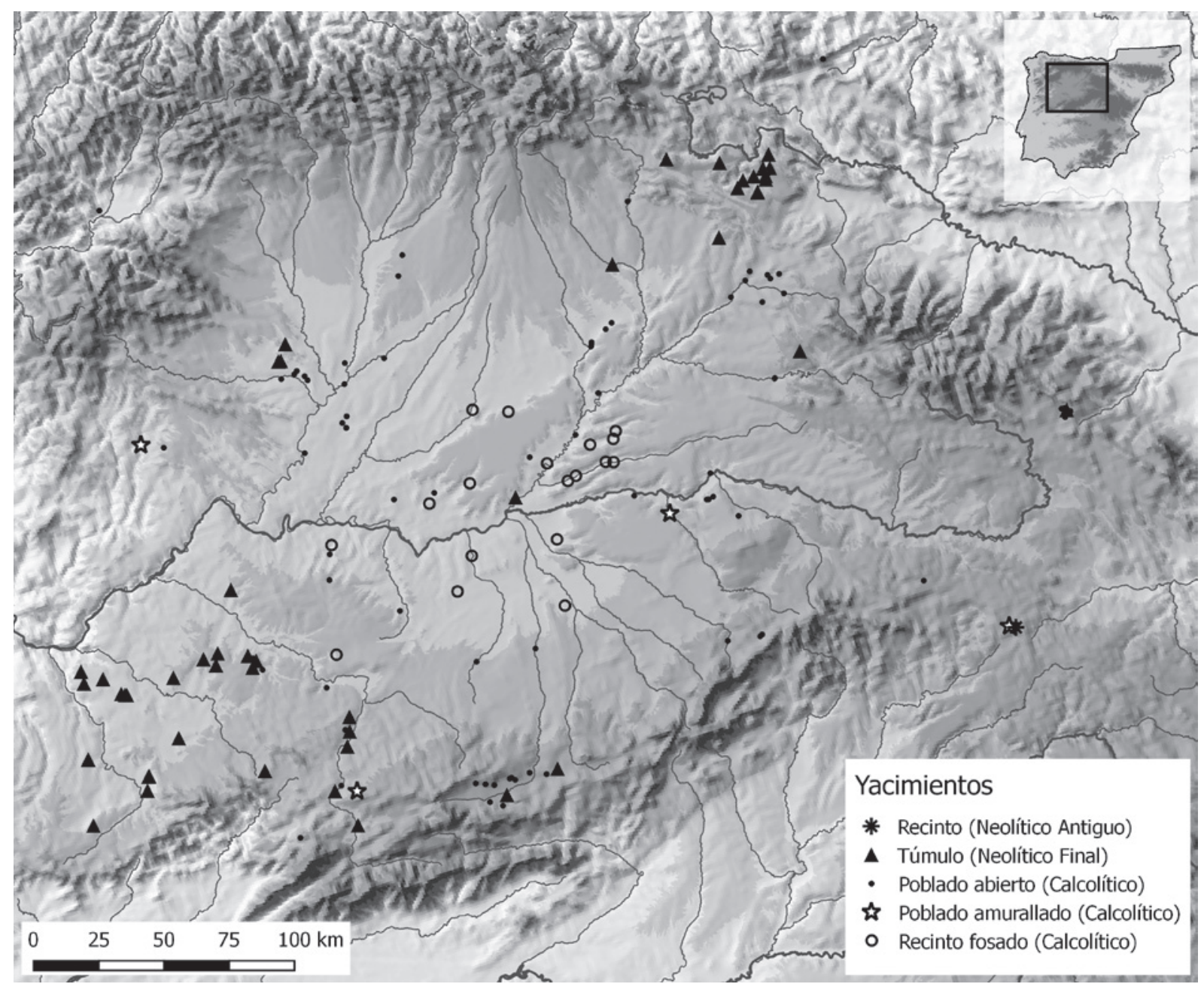

Figura 1. Mapa de distribución general de los yacimientos normeseteños analizados.

madera y otros materiales perecederos (Delibes de Castro y Santonja Gómez 1986: 155-158, Arias González 1989, Delibes de Castro et al. 1993: 24-25). En cuanto a los recintos fosados solo conocemos la parte de ellos que fue excavada en el subsuelo, pero existen indicios que apuntan a que estos complejos monumentales normeseteños pudieron haber incluido, además, taludes paralelos al recorrido de los fosos (Delibes de Castro et al. 2014: cap. 5.4). En alguno de los yacimientos de este tipo del Valle del Tajo se han llegado a documentar unas posibles estructuras de techado (Díaz-del-Río 2003).

Otra cuestión a tener en cuenta es que estas construcciones no tuvieron necesariamente que ser erigidas en un único evento puntual en el tiempo. Por ejemplo, está firmemente establecido que algunos monumentos prehistóricos del Nuevo Mundo fueron resultado del trabajo desarrollado a lo largo de varias etapas
(Earle 1987: 290). En el caso de los megalitos normeseteños se han podido documentar modificaciones arquitectónicas de la estructura ortostática como la adición de corredores o la condenación de estos mismos y de las cámaras, entre otras (Villalobos García 2014b), aunque la mayor parte de estas parecen haberse realizado en el Calcolítico (Benet Jordana et al. 1997, Rojo Guerra et al. 2005, Carmona Ballestero et al. 2014, Tejedor Rodríguez 2014), bastante después de su momento de uso original. Al respecto de los túmulos solo hay un caso, el del dolmen de El Moreco (Huidobro, Burgos), en el que se ha identificado que hubo dos fases distintas de construcción (Delibes de Castro y Rojo Guerra 2002). Sobre si los recintos de fosos normeseteños se realizaron en una o varias fases todavía se conocen pocos datos. Las tres únicas dataciones radiocarbónicas calibradas a $2 \sigma$ de cada uno de los tres fosos del recinto de El Casetón 
de la Era se solapan en el lapso c 2600-2500 cal a.C. (Delibes de Castro et al. 2009, Gibaja Bao et al. 2012), lo que no permite confirmar si estos fueron o no coetáneos. Si miramos más allá de la Meseta Norte, podemos apuntar que el análisis estadístico de las dataciones radiocarbónicas de los fosos de Camino de Yeseras (San Fernando de Henares, Madrid) sugiere que su excavación fue realizada de forma escalonada (Balsera et al. 2015a), aunque debe tenerse en cuenta la diferencia de escala existente entre este recinto madrileño, cuyos fosos delimitarían una superficie de al menos 15 ha, y los normeseteños, cuyos valores máximos no alcanzan las 3,5 ha (Delibes de Castro et al. 2014: 123).

En tercer y último lugar, debe destacarse que el procedimiento por el que se estima la cantidad de trabajo a partir de la cuantificación de volúmenes excavados, construidos, etc. es a través de la extrapolación de los resultados de trabajos de arqueología experimental u observaciones etnográficas. Cada uno de los estudios que hemos mencionado en la introducción ha empleado los coeficientes de distintas fuentes, las cuales son resultado de experimentos u observaciones realizados con condiciones, duración, cuadrillas, herramientas, etc. heterogéneos. Este es un inconveniente que por el momento no es posible resolver. En nuestro análisis vamos a utilizar preferentemente los coeficientes sobre la excavación de zanjas, el transporte y fijado de postes y la construcción de túmulos y murallas que Peterson y Drennan (2012: 131-132) recopilan en una síntesis elaborada para favorecer la realización de comparativas interculturales. No nos es posible calcular el trabajo total invertido en el transporte de las losas megalíticas debido a que se desconoce su lugar de extracción y, por tanto, el recorrido por el que fueron trasladadas al monumento, pero sí tenemos la oportunidad de estimar el número mínimo de personas implicadas en su arrastre gracias a los coeficientes de varios experimentos que sintetizan J. M. Vázquez Varela y otros (1987:132). Hemos recogido las relaciones entre construcción y trabajo que aquí vamos a utilizar en la tabla 1, pero debido a los problemas antedichos con los coeficientes de transformación, en todos nuestros cálculos vamos a ofrecer también los datos brutos (volumen, masa, etc.).

\subsection{Análisis}

En este epígrafe describiremos la forma en que hemos cuantificado la construcción de las obras monumentales de la Prehistoria Reciente normeseteña que describimos en el punto 2 y les aplicaremos los coeficientes de transformación citados en el punto 3.1, con objeto de estimar, al menos, el mínimo trabajo que fue necesario para su construcción.

\subsubsection{Neolítico Antiguo}

La única obra colectiva que se conoce del Neolítico Antiguo normeseteño es el recinto de zanjas y empalizadas de La Revilla, para el que podemos calcular tanto el trabajo del volumen excavado como el dedicado a la colocación de los postes. El volumen excavado "Vexc" lo calcularemos mediante la siguiente fórmula, siendo "a" el ancho de las zanjas, "b" la profundidad y "c" la longitud total, es decir el perímetro del recinto:

$$
\operatorname{Vexc}=a \cdot b \cdot c
$$

En cuanto a los postes, es posible realizar una estimación de su número si asumimos que se hallarían hincados de forma continua y sin espacios entre sí y que su anchura sería la misma que la de la zanja. Así, el número de postes "Npos" vendría dado por la siguiente formula, siendo "a" el ancho de la zanja y "c" la longitud total del recinto:

$$
\text { Npos }=\frac{c}{a}
$$

En la tabla 2 recogemos los resultados de nuestros cálculos, que nos han ofrecido una estimación de unos 216 días-persona de trabajo total destinado a las obras de este yacimiento.

Tabla 1. Relación de coeficientes de transformación empleados en este trabajo para la estimación del trabajo dedicado a los monumentos prehistóricos.

\begin{tabular}{|l|l|c|c|}
\hline \multicolumn{1}{|c|}{ Tarea } & Cantidad & $\begin{array}{c}\text { Trabajo } \\
\text { (días-persona) }\end{array}$ & NMI \\
\hline Excavar zanjas & $1 \mathrm{~m}^{3}$ & 2,6 & - \\
\hline $\begin{array}{l}\text { Transportar y fijar } \\
\text { postes }\end{array}$ & 1 unidad & 0,13 & - \\
\hline Construir túmulo & $1 \mathrm{~m}^{3}$ & 5,25 & - \\
\hline Construir murallas & $1 \mathrm{~m}^{3}$ & 12,25 & - \\
\hline $\begin{array}{l}\text { Arrastrar losas con } \\
\text { rodillos }\end{array}$ & $1 \mathrm{t}$ & - & 6 \\
\hline $\begin{array}{l}\text { Arrastrar losas sin } \\
\text { rodillos }\end{array}$ & $1 \mathrm{t}$ & - & $16-22$ \\
\hline
\end{tabular}


Tabla 2. Cálculos realizados para estimar el trabajo dedicado al recinto del Neolítico Antiguo de La Revilla de Campo.

\begin{tabular}{|l|c|c|c|c|c|c|c|c|}
\hline \multirow{2}{*}{ Zanja } & \multicolumn{3}{|c|}{ Dimensiones $(\mathrm{m})$} & \multirow{2}{*}{$\begin{array}{c}\text { Vexc } \\
\left(\mathrm{m}^{3}\right)\end{array}$} & \multirow{2}{*}{$\begin{array}{c}\text { Postes } \\
(\mathrm{n})\end{array}$} & \multicolumn{3}{c|}{ Trabajo (días-persona) } \\
& Ancho & Profundo & Perímetro & & Excavar & Postes & TOTAL \\
\hline Interior & 0,2 & 0,3 & 50 & 3,00 & 250 & 15,75 & 33,33 & 49,08 \\
\hline Exterior 1 & 0,3 & 0,3 & 91 & 8,19 & 303 & 43,00 & 40,44 & 83,44 \\
\hline Exterior 2 & 0,3 & 0,3 & 91 & 8,19 & 303 & 43,00 & 40,44 & 83,44 \\
\hline TOTAL & & & & 19,38 & 857 & 101,75 & 114,22 & 215,97 \\
\hline
\end{tabular}

\section{Con rodillos}

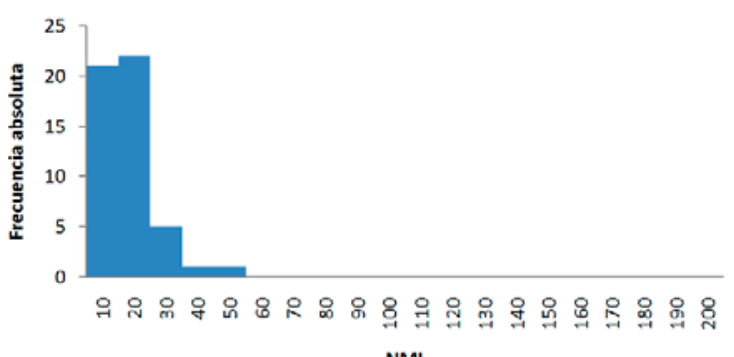

NMI
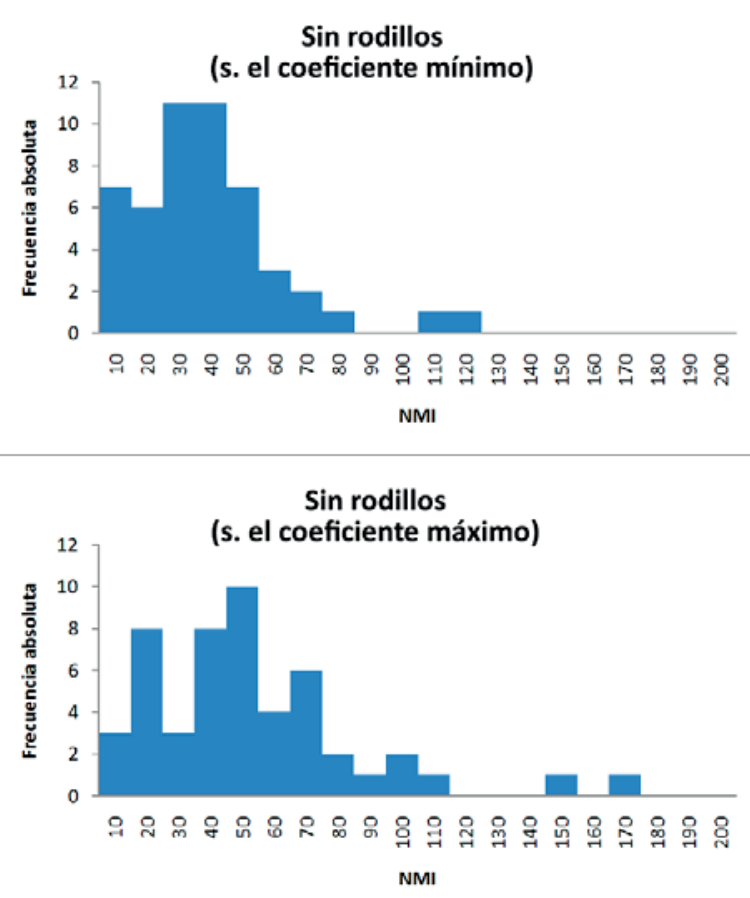

Figura 2. Histogramas con las distribuciones de NMI necesarios para el transporte del ortostostato mayor de los monumentos megalíticos del Neolítico Final según los distintos coeficientes.

\subsubsection{Neolítico Final}

Las lajas de los monumentos tardoneolíticos, dado que son una única pieza muy pesada y que, por tanto, requiere una gran fuerza para ser trasladada, son los únicos elementos de esta secuencia que nos ofrecen la posibilidad de calcular el tamaño mínimo de las cuadrillas de trabajo implicadas. Conociendo las dimensiones del ortostato mayor de cada megalito y su tipo de roca es posible calcular la masa máxima que fue movida para cada caso y, aplicando los distintos coeficientes, el número mínimo de personas involucradas.

Hemos tomado el tamaño de los ortostatos de la bibliografía referida en el punto 2 , ya sea, preferentemente, atendiendo a las dimensiones expresadas de forma explícita o, en caso de que esto no haya sido posible, midiéndolas en las planimetrías escaladas. Para deducir su volumen hemos asimilado las lajas a la forma de un prisma cuadrangular ideal y, para traducir el volumen en peso, hemos usado las densidades de rocas empleadas para la construcción que recoge el manual técnico de Siegesmund y Snethlage (2011, tab. 3.1 y fig. 3.1). En la tabla 3 se recogen nuestros cálculos y en la figura 2 mostramos de forma gráfica la distribución de los valores del NMI requeridos por megalito, donde podemos observar que, aun si tomamos el coeficiente menos conservador -más personal por unidad de masa-, la gran mayoría de estos no habrían precisado de un grupo de trabajo superior al centenar de personas.

El otro aspecto en el que podemos indagar es en el trabajo total dedicado a la construcción del túmulo. Para calcular los volúmenes hemos empleado los datos publicados anteriormente referidos, considerando el túmulo como un casquete de esfera ideal, siendo el radio y altura del túmulo respectivamente el radio y altura del casquete. En el caso de túmulos erigidos sobre promontorios naturales, hemos tomado como 
Tabla 3. Cálculos realizados para estimar el número mínimo de individuos necesarios para el transporte del ortostato mayor de los monumentos megalíticos del Neolítico Final.

\begin{tabular}{|c|c|c|c|c|c|c|c|c|c|c|c|}
\hline \multirow{3}{*}{ Nombre } & \multirow{3}{*}{ Zona } & \multicolumn{7}{|c|}{ Ortostato mayor } & \multirow{2}{*}{\multicolumn{3}{|c|}{$\begin{array}{l}\text { Número mínimo de individuos nece- } \\
\text { sarios para arrastrar el ortostato }\end{array}$}} \\
\hline & & \multicolumn{3}{|c|}{ Dimensiones (m) } & \multirow{2}{*}{$\begin{array}{l}\text { Vol. } \\
\left(\mathrm{m}^{3}\right)\end{array}$} & \multicolumn{2}{|c|}{ Materia Prima } & \multirow{2}{*}{$\begin{array}{c}\text { Masa } \\
(\mathrm{kg})\end{array}$} & & & \\
\hline & & a & $\mathrm{b}$ & $\mathrm{c}$ & & Tipo & $\begin{array}{c}\text { Densidad } \\
\left(\mathrm{kg} / \mathrm{m}^{3}\right)\end{array}$ & & $\begin{array}{l}\text { Con } \\
\text { rodillos }\end{array}$ & $\begin{array}{l}\text { Sin rodillos } \\
(\mathrm{min})\end{array}$ & $\begin{array}{l}\text { Sin rodillos } \\
\quad(\max )\end{array}$ \\
\hline Los Zumacales & $\mathrm{C}$ & 1,3 & 1,2 & 0,5 & 0,78 & Caliza & 2400 & 1.872 & 11 & 30 & 41 \\
\hline La Velilla & $\mathrm{C}$ & 2,1 & 1,6 & 0,3 & 1,008 & Caliza & 2400 & 2.419 & 15 & 39 & 53 \\
\hline El Alto de la Tejera & E & 2,0 & 2,0 & 0,3 & 1,2 & Arenisca & 2690 & 3.228 & 19 & 52 & 71 \\
\hline Fuentepecina I & $\mathrm{NE}$ & 0,7 & 0,9 & 0,3 & 0,189 & Caliza & 2400 & 454 & 3 & 7 & 10 \\
\hline Fuentepecina II & $\mathrm{NE}$ & 1,1 & 1,0 & 0,2 & 0,22 & Caliza & 2400 & 528 & 3 & 8 & 12 \\
\hline Valdemuriel & $\mathrm{NE}$ & 1,1 & 1,6 & 0,2 & 0,352 & Caliza & 2400 & 845 & 5 & 14 & 19 \\
\hline El Corral & $\mathrm{NE}$ & 1,0 & 1,4 & 0,3 & 0,42 & Caliza & 2400 & 1.008 & 6 & 16 & 22 \\
\hline Las Arnillas & $\mathrm{NE}$ & 2,0 & 1,5 & 0,2 & 0,6 & Caliza & 2400 & 1.440 & 9 & 23 & 32 \\
\hline San Quirce & NE & 2,0 & 1,6 & 0,2 & 0,64 & Caliza & 2400 & 1.536 & 9 & 25 & 34 \\
\hline Cista de la Nava Alta & $\mathrm{NE}$ & 1,0 & 2,2 & 0,3 & 0,66 & Caliza & 2400 & 1.584 & 10 & 25 & 35 \\
\hline La Cotorrita & $\mathrm{NE}$ & 2,8 & 1,2 & 0,2 & 0,672 & Caliza & 2400 & 1.613 & 10 & 26 & 35 \\
\hline El Moreco & $\mathrm{NE}$ & 1,7 & 1,4 & 0,3 & 0,714 & Caliza & 2400 & 1.714 & 10 & 27 & 38 \\
\hline Ciella & $\mathrm{NE}$ & 1,6 & 1,6 & 0,3 & 0,768 & Caliza & 2400 & 1.843 & 11 & 29 & 41 \\
\hline La Nava Negra & $\mathrm{NE}$ & 2,0 & 1,5 & 0,3 & 0,9 & Caliza & 2400 & 2.160 & 13 & 35 & 48 \\
\hline La Cabaña & $\mathrm{NE}$ & 2,0 & 1,5 & 0,3 & 0,9 & Caliza & 2400 & 2.160 & 13 & 35 & 48 \\
\hline Cubillejo de Lara & $\mathrm{NE}$ & 2,3 & 1,6 & 0,4 & 1,472 & Caliza & 2400 & 3.533 & 21 & 57 & 78 \\
\hline Dehesa de Río Fortes & SW & 1,3 & 0,4 & 0,2 & 0,104 & Granito & 2660 & 277 & 2 & 4 & 6 \\
\hline Pedro Toro & SW & 0,9 & 0,6 & 0,3 & 0,162 & $?$ & 2660 & 431 & 3 & 7 & 9 \\
\hline El Torrión & SW & 1,0 & 0,9 & 0,2 & 0,18 & Granito & 2660 & 479 & 3 & 8 & 11 \\
\hline Rábida I & SW & 1,3 & 0,7 & 0,2 & 0,182 & Cuarcita & 2690 & 490 & 3 & 8 & 11 \\
\hline Las Eras & SW & 1,8 & 0,4 & 0,3 & 0,216 & Cuarcita & 2690 & 581 & 3 & 9 & 13 \\
\hline Nava del Rocío & SW & 1,0 & 0,7 & 0,4 & 0,28 & Granito & 2660 & 745 & 4 & 12 & 16 \\
\hline La Ermita & SW & 1,9 & 0,8 & 0,2 & 0,304 & Cuarcita & 2690 & 818 & 5 & 13 & 18 \\
\hline Prado de las Cruces & SW & 1,7 & 1,0 & 0,2 & 0,34 & Granito & 2660 & 904 & 5 & 14 & 20 \\
\hline $\begin{array}{l}\text { Ermita Vega de } \\
\text { Sepúlveda }\end{array}$ & SW & 1,0 & 0,7 & 0,5 & 0,35 & Cuarcita & 2690 & 942 & 6 & 15 & 21 \\
\hline El Teriñuelo & SW & 1,5 & 1,1 & 0,3 & 0,495 & Cuarcita & 2690 & 1.332 & 8 & 21 & 29 \\
\hline Valle de las Cañas & SW & 1,5 & 0,9 & 0,4 & 0,54 & Cuarcita & 2690 & 1.453 & 9 & 23 & 32 \\
\hline $\begin{array}{l}\text { Los Pedazos de la } \\
\text { Mata }\end{array}$ & SW & 1,9 & 1,0 & 0,3 & 0,57 & Granito & 2660 & 1.516 & 9 & 24 & 33 \\
\hline
\end{tabular}

Continúa en la página siguiente 


\begin{tabular}{|c|c|c|c|c|c|c|c|c|c|c|c|}
\hline \multirow{3}{*}{ Nombre } & \multirow{3}{*}{ Zona } & \multicolumn{7}{|c|}{ Ortostato mayor } & \multirow{2}{*}{\multicolumn{3}{|c|}{$\begin{array}{l}\text { Número mínimo de individuos nece- } \\
\text { sarios para arrastrar el ortostato }\end{array}$}} \\
\hline & & \multicolumn{3}{|c|}{ Dimensiones (m) } & \multirow{2}{*}{$\begin{array}{l}\text { Vol. } \\
\left(\mathrm{m}^{3}\right)\end{array}$} & \multicolumn{2}{|c|}{ Materia Prima } & \multirow{2}{*}{$\begin{array}{c}\text { Masa } \\
(\mathrm{kg})\end{array}$} & & & \\
\hline & & $\mathrm{a}$ & $\mathrm{b}$ & $\mathrm{c}$ & & Tipo & $\begin{array}{c}\text { Densidad } \\
\left(\mathrm{kg} / \mathrm{m}^{3}\right)\end{array}$ & & $\begin{array}{l}\text { Con } \\
\text { rodillos }\end{array}$ & $\begin{array}{l}\text { Sin rodillos } \\
(\mathrm{min})\end{array}$ & $\begin{array}{l}\text { Sin rodillos } \\
(\max )\end{array}$ \\
\hline Rábida II & SW & 1,7 & 0,9 & 0,4 & 0,612 & $?$ & 2660 & 1.628 & 10 & 26 & 36 \\
\hline Guijo de las Navas I & SW & 1,2 & 1,5 & 0,4 & 0,72 & Granito & 2660 & 1.915 & 11 & 31 & 42 \\
\hline Las Peñezuelas & SW & 1,8 & 1,0 & 0,4 & 0,72 & Cuarcita & 2690 & 1.937 & 12 & 31 & 43 \\
\hline Castillejo I & SW & 2,0 & 1,2 & 0,3 & 0,72 & Cuarcita & 2690 & 1.937 & 12 & 31 & 43 \\
\hline Casa del Moro & SW & 1,8 & 1,4 & 0,3 & 0,756 & Granito & 2660 & 2.011 & 12 & 32 & 44 \\
\hline Torrecilla & SW & 1,6 & 1,5 & 0,3 & 0,72 & Pizarra & 2800 & 2.016 & 12 & 32 & 44 \\
\hline La Casa de los Moros & SW & 2,2 & 1,2 & 0,3 & 0,792 & Granito & 2660 & 2.107 & 13 & 34 & 46 \\
\hline El Torrejón & SW & 3,2 & 0,9 & 0,3 & 0,864 & Granito & 2660 & 2.298 & 14 & 37 & 51 \\
\hline La Casa de los Moros & SW & 1,5 & 2,0 & 0,3 & 0,9 & Cuarcita & 2690 & 2.421 & 15 & 39 & 53 \\
\hline Sahelicejos & SW & 2,0 & 1,7 & 0,3 & 1,02 & Granito & 2660 & 2.713 & 16 & 43 & 60 \\
\hline Zafrón & SW & 1,6 & 1,3 & 0,5 & 1,04 & Granito & 2660 & 2.766 & 17 & 44 & 61 \\
\hline La Navalito & SW & 3,3 & 1,6 & 0,2 & 1,056 & Granito & 2660 & 2.809 & 17 & 45 & 62 \\
\hline Casa del Moro II & SW & 2,1 & 1,7 & 0,3 & 1,071 & Granito & 2660 & 2.849 & 17 & 46 & 63 \\
\hline La Veguilla I & SW & 1,6 & 1,4 & 0,5 & 1,12 & Granito & 2660 & 2.979 & 18 & 48 & 66 \\
\hline El Rodeo & SW & 1,1 & 1,3 & 0,8 & 1,144 & $?$ & 2660 & 3.043 & 18 & 49 & 67 \\
\hline Los Castillos II & SW & 1,8 & 3,2 & 0,2 & 1,152 & $?$ & 2660 & 3.064 & 18 & 49 & 67 \\
\hline Piedras Hincadas & SW & 2,7 & 1,3 & 0,4 & 1,404 & $?$ & 2660 & 3.735 & 22 & 60 & 82 \\
\hline Casal del Gato & SW & 2,4 & 1,3 & 0,5 & 1,56 & Granito & 2660 & 4.150 & 25 & 66 & 91 \\
\hline Hondura & SW & 2,0 & 1,0 & 0,8 & 1,6 & Cuarcita & 2690 & 4.304 & 26 & 69 & 95 \\
\hline San Adrián & SW & 1,9 & 1,6 & 0,6 & 1,824 & Cuarcita & 2690 & 4.907 & 29 & 79 & 108 \\
\hline $\begin{array}{l}\text { La Huerta de las Áni- } \\
\text { mas }\end{array}$ & SW & 2,4 & 1,2 & 0,8 & 2,304 & Pizarra & 2800 & 6.451 & 39 & 103 & 142 \\
\hline Los Castillos & SW & 2,9 & 2,4 & 0,4 & 2,784 & Granito & 2660 & 7.405 & 44 & 118 & 163 \\
\hline
\end{tabular}

altura la existente desde el suelo natural hasta la cima del túmulo con objeto de no sobredimensionarlo. Para aquellos monumentos en los que el túmulo ha sido parcialmente destruido por afecciones posteriores, hemos tomado el radio mayor conservado. Al igual que con los ortostatos, en aquellos casos en los que las dimensiones no se expresaban explícitamente en la bibliografía las hemos extraído de las planimetrías escaladas. Hemos aplicado la siguiente fórmula para hallar el volumen del casquete de esfera, siendo "Vcas" el volumen del casquete esférico, "h" la altura y "a" el radio del túmulo:

$$
\operatorname{Vcas}=\frac{\pi \cdot h}{6}\left(3 a^{2}+h^{2}\right)
$$

Para obtener el volumen total del túmulo, no obstante, debemos restarle a "Vcas" el volumen de la cámara y el corredor, pues lógicamente son espacios donde no hubo túmulo construido (fig. 3). Para la cámara hemos calculado su volumen asimilándola a un cilindro ideal. En los pocos casos de cámaras ovaladas hemos deducido el diámetro como la media del diámetro mayor y el diámetro menor. Cuando en la 
Figura 3. Esquema de las abstracciones geométricas mediante las que hemos calculado el volumen del túmulo (diseño malla 3D Javier Duque).

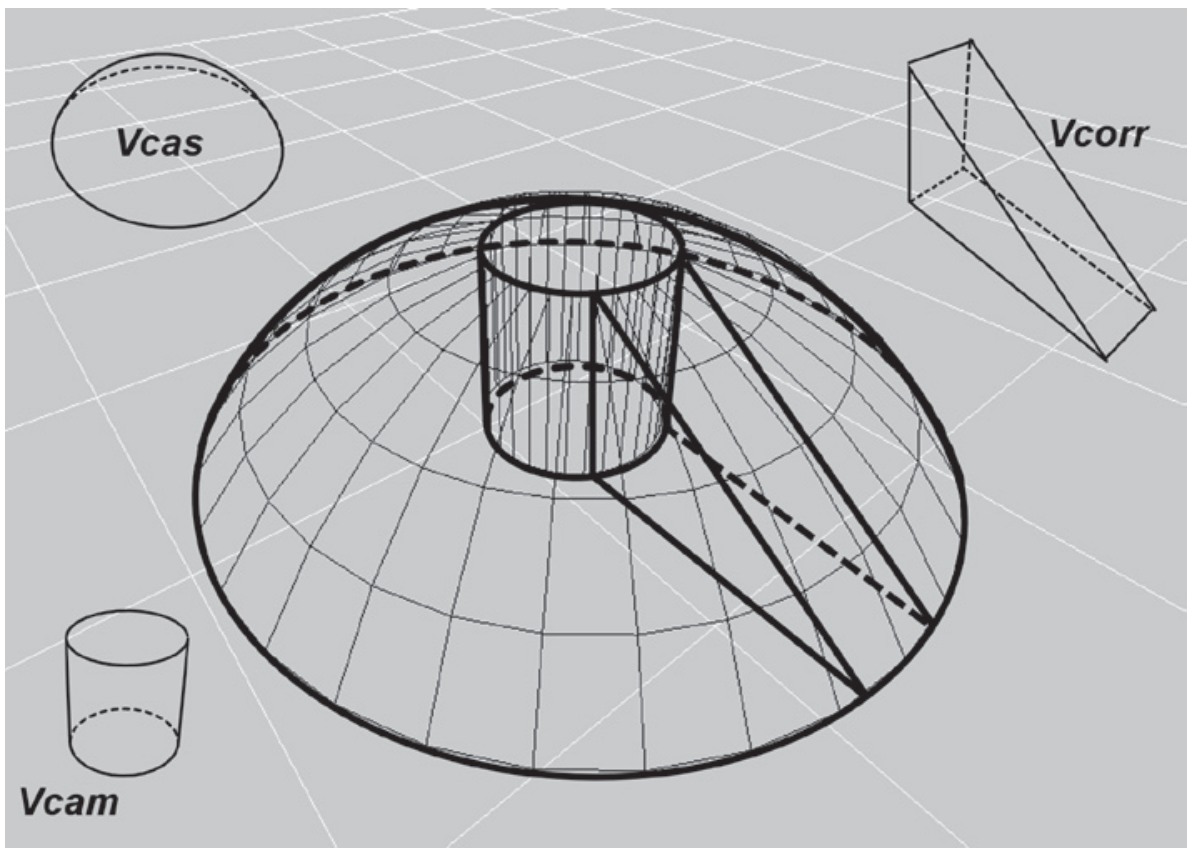

publicación no se expresaban las dimensiones de la cámara pero sí del túmulo hemos considerado que la cámara mediría 1/6 del total del túmulo, la mediana de la distribución de la relación entre cámara y túmulo que hemos identificado en el resto de monumentos. Así, hemos aplicado la fórmula que sigue, siendo "Vcam" el volumen de la cámara, "r" el radio y "h" la altura:

$$
\operatorname{Vcam}=\pi \cdot r^{2} \cdot h
$$

En cuanto al corredor, hemos considerado un medio prisma cuadrangular truncado en diagonal, siendo las aristas de la base del prisma la altura y anchura del corredor. Puesto que los corredores oscilan entre 0,8 y 1,2 $\mathrm{m}$ de anchura emplearemos, para simplificar, $1 \mathrm{~m}$ en todos los casos y, para la altura del corredor, emplearemos la altura del túmulo. La altura del prisma será la longitud del corredor, que consideramos es la distancia entre el perímetro del túmulo y el punto donde conectan corredor y cámara. La fórmula que hemos aplicado ha sido la siguiente, siendo "Vcorr" el volumen del corredor, "a" y "b" los dos lados de la base del prisma y "h" la altura del prisma:

$$
\operatorname{Vorr}=\frac{a \cdot b \cdot h}{2}
$$

El volumen del túmulo total construido (Vtum), por tanto, vendrá dado por la siguiente fórmula:

$$
\text { Vtum }=\text { Vcas }-(\text { Vcam }+ \text { Vcorr })
$$

Los resultados de la aplicación de estas fórmulas a las dimensiones de los túmulos normeseteños, así como la transformación de volumen a trabajo destinado a su construcción mediante el coeficiente anteriormente descrito, se encuentran recogidos en la tabla 4. En esta y en la gráfica de la fig. 4, que muestra la distribución de los valores del trabajo invertido por cada yacimiento, se puede identificar que más de un tercio de estos monumentos son pequeños túmulos en los que no se dedicaron más de 500 días-persona y que el $90 \%$ del total requirió menos de 4.000 días-persona.

\subsubsection{Calcolítico}

Como ya hemos relatado, en el Calcolítico normeseteño podemos encontrarnos con poblados amurallados y con recintos fosados. Los primeros son muy escasos, pero es posible estimar el trabajo invertido en al menos dos de ellos, que son la muralla de El Pedroso y la muralla y el foso de El Alto del Quemado. Para el volumen de la muralla (Vmur) hemos aplicado la siguiente fórmula, siendo "a" su espesor, "b" su altura y "c" la longitud de la fortificación:

$$
\text { Vmur }=a \cdot b \cdot c
$$


Tabla 4. Cálculos realizados para estimar el trabajo dedicado a la construcción de los túmulos del Neolítico Final.

\begin{tabular}{|c|c|c|c|c|c|c|c|c|c|}
\hline \multirow[b]{2}{*}{ Nombre } & \multirow[b]{2}{*}{ Zona } & \multicolumn{3}{|c|}{ Dimensiones (m) } & \multicolumn{4}{|c|}{ Volúmenes $\left(\mathrm{m}^{3}\right)$} & \multirow{2}{*}{$\begin{array}{l}\text { Trabajo (días- } \\
\text { persona) }\end{array}$} \\
\hline & & $\begin{array}{l}\text { Radio } \\
\text { cámara }\end{array}$ & $\begin{array}{l}\text { Radio } \\
\text { túmulo }\end{array}$ & $\begin{array}{l}\text { Altura } \\
\text { túmulo }\end{array}$ & Vcas & Vcam & Vcorr & Vtum & \\
\hline El Miradero & $\mathrm{C}$ & $1,25^{*}$ & 7,50 & 0,70 & 62,03 & 3,44 & 2,41 & 56,19 & 295 \\
\hline La Velilla & $\mathrm{C}$ & 1,00 & 10,00 & 0,50 & 78,60 & 1,57 & 2,38 & 74,66 & 392 \\
\hline Los Zumacales & $\mathrm{C}$ & 2,60 & 15,00 & 1,00 & 353,94 & 21,24 & 6,85 & 325,86 & 1.711 \\
\hline La Tarayuela & $\mathrm{E}$ & $0,68 *$ & 4,05 & 0,40 & 10,34 & 0,57 & 0,74 & 9,02 & 47 \\
\hline El Alto de la Tejera & E & 1,45 & 9,00 & 0,80 & 102,05 & 5,28 & 3,31 & 93,46 & 491 \\
\hline La Peña de la Abuela & $\mathrm{E}$ & 4,00 & 10,00 & 1,50 & 237,38 & 75,40 & 6,00 & 155,98 & 819 \\
\hline San Gregorio & E & $2,08^{*}$ & 12,50 & 1,50 & 369,91 & 20,45 & 8,59 & 340,87 & 1.790 \\
\hline El Túmulo de la Sima & $\mathrm{E}$ & 2,25 & 12,50 & 2,20 & 545,52 & 34,99 & 12,51 & 498,02 & 2.615 \\
\hline Calar de la Congostura III & NE & $0,58^{*}$ & 3,50 & 0,40 & 7,73 & 0,43 & 0,64 & 6,66 & 35 \\
\hline Atapuerca III & $\mathrm{NE}$ & $0,83^{*}$ & 5,00 & 0,25 & 9,83 & 0,55 & 0,57 & 8,71 & 46 \\
\hline Cista de la Nava Alta & $\mathrm{NE}$ & 1,15 & 3,00 & 1,00 & 14,66 & 4,15 & 1,21 & 9,29 & 49 \\
\hline La Lanchera & NE & $0,83^{*}$ & 5,00 & 0,30 & 11,79 & 0,65 & 0,69 & 10,45 & 55 \\
\hline Calar de la Congostura II & NE & $0,75^{*}$ & 4,50 & 0,40 & 12,76 & 0,71 & 0,83 & 11,22 & 59 \\
\hline Fuentepecina IV & NE & $0,83^{*}$ & 5,00 & 0,50 & 19,70 & 1,09 & 1,15 & 17,46 & 92 \\
\hline La Calera II & NE & $0,71^{*}$ & 4,25 & 0,70 & 20,04 & 1,10 & 1,36 & 17,57 & 92 \\
\hline Cuesta Rubia & $\mathrm{NE}$ & $0,83^{*}$ & 5,00 & 0,80 & 31,68 & 1,75 & 1,83 & 28,10 & 148 \\
\hline La Congostura & $\mathrm{NE}$ & $0,92 *$ & 5,50 & 0,70 & 33,44 & 1,85 & 1,76 & 29,83 & 157 \\
\hline Revelillas & $\mathrm{NE}$ & 1,50 & 5,00 & 1,00 & 39,79 & 7,07 & 2,13 & 30,60 & 161 \\
\hline Calar de la Congostura I & $\mathrm{NE}$ & $0,92 *$ & 5,50 & 0,80 & 38,28 & 2,11 & 2,02 & 34,15 & 179 \\
\hline El Rebolledo & $\mathrm{NE}$ & $0,67^{*}$ & 4,00 & 1,50 & 39,47 & 2,09 & 2,75 & 34,62 & 182 \\
\hline Atapuerca IV & $\mathrm{NE}$ & $1,29 *$ & 7,75 & 0,50 & 47,24 & 2,62 & 1,78 & 42,84 & 225 \\
\hline Tañuga & NE & $1,04^{*}$ & 6,25 & 0,80 & 49,35 & 2,73 & 2,29 & 44,34 & 233 \\
\hline Portal Ancho & $\mathrm{NE}$ & $0,92 *$ & 5,50 & 1,10 & 52,96 & 2,90 & 2,77 & 47,29 & 248 \\
\hline Fuentepecina III & $\mathrm{NE}$ & $1,00^{*}$ & 6,00 & 1,00 & 57,07 & 3,14 & 2,75 & 51,18 & 269 \\
\hline El Corral & $\mathrm{NE}$ & 1,50 & 9,00 & 0,60 & 76,45 & 4,24 & 2,48 & 69,74 & 366 \\
\hline Casavegas & $\mathrm{NE}$ & $1,17^{*}$ & 7,00 & 1,00 & 77,49 & 4,28 & 3,21 & 70,01 & 368 \\
\hline Fuentepecina I & NE & 1,25 & 7,50 & 1,00 & 88,88 & 4,91 & 3,44 & 80,53 & 423 \\
\hline Arroyal I & $\mathrm{NE}$ & $1,40^{*}$ & 6,00 & 1,80 & 104,84 & 11,08 & 4,77 & 88,98 & 467 \\
\hline Nava de las Hoyas & $\mathrm{NE}$ & $1,00 *$ & 6,00 & 1,80 & 104,84 & 5,65 & 4,95 & 94,23 & 495 \\
\hline
\end{tabular}

*Cámaras cuyas dimensiones exactas desconocemos y que hemos calculado mediante la relación de un sexto respecto al túmulo. 


\begin{tabular}{|c|c|c|c|c|c|c|c|c|c|}
\hline \multirow[b]{2}{*}{ Nombre } & \multirow[b]{2}{*}{ Zona } & \multicolumn{3}{|c|}{ Dimensiones (m) } & \multicolumn{4}{|c|}{ Volúmenes $\left(\mathrm{m}^{3}\right)$} & \multirow{2}{*}{$\begin{array}{c}\text { Trabajo (días } \\
\text { persona) }\end{array}$} \\
\hline & & $\begin{array}{l}\text { Radio } \\
\text { cámara }\end{array}$ & $\begin{array}{l}\text { Radio } \\
\text { túmulo }\end{array}$ & $\begin{array}{l}\text { Altura } \\
\text { túmulo }\end{array}$ & Vcas & Vcam & Vcorr & Vtum & \\
\hline Alto del Corral & $\mathrm{NE}$ & $1,61^{*}$ & 9,65 & 0,80 & 117,29 & 6,50 & 3,54 & 107,25 & 563 \\
\hline Fuentepecina II & $\mathrm{NE}$ & 1,25 & 7,38 & 1,50 & 129,92 & 7,36 & 5,06 & 117,49 & 617 \\
\hline San Quirce & $\mathrm{NE}$ & 1,25 & 8,00 & 1,50 & 152,56 & 7,36 & 5,53 & 139,66 & 733 \\
\hline Valdemuriel & $\mathrm{NE}$ & 1,00 & 8,00 & 1,60 & 162,99 & 5,03 & 6,00 & 151,96 & 798 \\
\hline La Mina & $\mathrm{NE}$ & $1,46^{*}$ & 8,75 & 1,50 & 182,16 & 10,02 & 6,02 & 166,12 & 872 \\
\hline Ciella & $\mathrm{NE}$ & 1,75 & 9,00 & 1,50 & 192,61 & 14,43 & 6,09 & 172,09 & 903 \\
\hline La Nava Negra & $\mathrm{NE}$ & 1,50 & 8,00 & 2,00 & 205,24 & 14,14 & 7,25 & 183,86 & 965 \\
\hline El Silo & $\mathrm{NE}$ & $1,67^{*}$ & 10,00 & 2,00 & 318,34 & 17,45 & 9,17 & 291,72 & 1.532 \\
\hline Turrumbero Cañada & $\mathrm{NE}$ & 1,45 & 12,50 & 1,30 & 320,21 & 8,59 & 7,65 & 303,97 & 1.596 \\
\hline La Cabaña & $\mathrm{NE}$ & 1,60 & 11,00 & 2,00 & 384,31 & 16,08 & 10,20 & 358,03 & 1.880 \\
\hline La Cotorrita & $\mathrm{NE}$ & 1,35 & 10,00 & 3,00 & 485,36 & 17,18 & 13,99 & 454,20 & 2.385 \\
\hline El Moreco & $\mathrm{NE}$ & 2,00 & 13,50 & 2,20 & 635,37 & 27,65 & 13,75 & 593,97 & 3.118 \\
\hline Turrumbero de Arriba & $\mathrm{NE}$ & $2,67^{*}$ & 16,00 & 1,60 & 645,52 & 35,74 & 11,73 & 598,05 & 3.140 \\
\hline La Brújula & $\mathrm{NE}$ & 0,75 & 15,00 & 1,85 & 657,14 & 3,27 & 13,53 & 640,34 & 3.362 \\
\hline Cubillejo de Lara & $\mathrm{NE}$ & 2,43 & 16,00 & 2,30 & 931,23 & 42,49 & 17,01 & 871,73 & 4.577 \\
\hline Las Arnillas & $\mathrm{NE}$ & 1,75 & 18,75 & 2,00 & $1.108,62$ & 19,24 & 17,88 & $1.071,51$ & 5.625 \\
\hline Guijo de las Navas I & SW & 0,60 & 2,00 & 0,60 & 3,88 & 0,68 & 0,51 & 2,69 & 14 \\
\hline Cuarto de las Cabezas & SW & $0,83^{*}$ & 5,00 & 0,80 & 31,68 & 1,75 & 1,83 & 28,10 & 148 \\
\hline Castillejo II & SW & $1,00 *$ & 6,00 & 0,60 & 34,04 & 1,88 & 1,65 & 30,51 & 160 \\
\hline El Castillejo & SW & $0,92 *$ & 5,50 & 1,00 & 48,04 & 2,64 & 2,52 & 42,88 & 225 \\
\hline Ermita Vega Sepúlveda II & SW & $1,33^{*}$ & 8,00 & 0,50 & 50,33 & 2,79 & 1,83 & 45,70 & 240 \\
\hline El Guejo Diego Gómez & SW & $1,17^{*}$ & 7,00 & 1,00 & 77,49 & 4,28 & 3,21 & 70,01 & 368 \\
\hline El Raso & SW & $1,13^{*}$ & 6,75 & 1,30 & 94,19 & 5,17 & 4,02 & 85,00 & 446 \\
\hline Carrascalino & SW & $1,29 *$ & 7,75 & 1,00 & 94,87 & 5,24 & 3,55 & 86,07 & 452 \\
\hline Castillejo I & SW & 1,30 & 7,75 & 1,50 & 143,28 & 7,96 & 5,33 & 129,99 & 682 \\
\hline Prado de las Cruces & SW & 1,75 & 11,00 & 0,80 & 152,32 & 7,70 & 4,05 & 140,57 & 738 \\
\hline Casa del Moro I & SW & 2,00 & 7,50 & 2,00 & 180,90 & 25,13 & 6,50 & 149,27 & 784 \\
\hline Los Huelmos II & SW & $1,83^{*}$ & 11,00 & 1,00 & 190,58 & 10,56 & 5,04 & 174,98 & 919 \\
\hline Prado Nuevo & SW & $1,61^{*}$ & 9,65 & 1,40 & 206,22 & 11,38 & 6,19 & 188,65 & 990 \\
\hline Cuadrilleros & SW & $1,75^{*}$ & 10,50 & 1,20 & 208,71 & 11,55 & 5,78 & 191,39 & 1.005 \\
\hline
\end{tabular}

*Cámaras cuyas dimensiones exactas desconocemos y que hemos calculado mediante la relación de un sexto respecto al túmulo. 


\begin{tabular}{|c|c|c|c|c|c|c|c|c|c|}
\hline \multirow[b]{2}{*}{ Nombre } & \multirow[b]{2}{*}{ Zona } & \multicolumn{3}{|c|}{ Dimensiones (m) } & \multicolumn{4}{|c|}{ Volúmenes $\left(\mathrm{m}^{3}\right)$} & \multirow{2}{*}{$\begin{array}{l}\text { Trabajo (días- } \\
\text { persona) }\end{array}$} \\
\hline & & $\begin{array}{l}\text { Radio } \\
\text { cámara }\end{array}$ & $\begin{array}{l}\text { Radio } \\
\text { túmulo }\end{array}$ & $\begin{array}{l}\text { Altura } \\
\text { túmulo }\end{array}$ & Vcas & Vcam & Vcorr & Vtum & \\
\hline Las Peñicas & SW & $1,50 *$ & 9,00 & 1,70 & 218,86 & 12,02 & 7,01 & 199,84 & 1.049 \\
\hline La Casa de los Moros & SW & 2,25 & 12,50 & 1,00 & 245,95 & 15,90 & 5,69 & 224,36 & 1.178 \\
\hline La Veguilla II & SW & $2,08^{*}$ & 12,50 & 1,00 & 245,95 & 13,63 & 5,73 & 226,59 & 1.190 \\
\hline El Teriñuelo & SW & $1,92 *$ & 11,50 & 1,20 & 250,18 & 13,85 & 6,33 & 230,01 & 1.208 \\
\hline El Juncal II & SW & $1,67^{*}$ & 10,00 & 2,00 & 318,34 & 17,45 & 9,17 & 291,72 & 1.532 \\
\hline Los Torrejones & SW & $2,50 *$ & 15,00 & 1,00 & 353,94 & 19,63 & 6,88 & 327,43 & 1.719 \\
\hline El Tiriñuelo & SW & $2,21 *$ & 13,25 & 1,50 & 415,41 & 22,98 & 9,11 & 383,32 & 2.012 \\
\hline El Rodeo & SW & $2,00^{*}$ & 12,00 & 2,00 & 456,56 & 25,13 & 11,00 & 420,43 & 2.207 \\
\hline Prado de la Nava & SW & 2,25 & 12,75 & 1,80 & 462,67 & 28,63 & 10,46 & 423,59 & 2.224 \\
\hline El Caño & SW & $1,79^{*}$ & 10,75 & 2,50 & 461,98 & 25,21 & 12,32 & 424,45 & 2.228 \\
\hline Linejo & SW & 1,95 & 15,50 & 1,20 & 453,75 & 14,33 & 8,72 & 430,70 & 2.261 \\
\hline La Ermita & SW & 1,75 & 12,25 & 2,00 & 475,61 & 19,24 & 11,38 & 444,99 & 2.336 \\
\hline El Teso del Oro & SW & $2,08 *$ & 12,50 & 2,00 & 495,05 & 27,27 & 11,46 & 456,32 & 2.396 \\
\hline Casa del Moro & SW & 1,65 & 14,50 & 1,50 & 497,14 & 12,83 & 10,26 & 474,06 & 2.489 \\
\hline El Mesón & SW & $2,17^{*}$ & 13,00 & 2,00 & 535,10 & 29,50 & 11,92 & 493,69 & 2.592 \\
\hline La Veguilla I & SW & 2,50 & 14,25 & 2,00 & 642,11 & 39,27 & 13,00 & 589,84 & 3.097 \\
\hline El Turrión & SW & $2,13^{*}$ & 12,75 & 2,50 & 646,54 & 35,46 & 14,61 & 596,47 & 3.131 \\
\hline Ermita Vega Sepúlveda I & SW & 1,25 & 14,25 & 2,00 & 642,11 & 9,82 & 13,63 & 618,67 & 3.248 \\
\hline Hondura & SW & 1,28 & 14,00 & 2,20 & 682,88 & 11,24 & 14,70 & 656,95 & 3.449 \\
\hline El Canturral & SW & $2,50 *$ & 15,00 & 2,00 & 711,03 & 39,27 & 13,75 & 658,01 & 3.455 \\
\hline El Torrión & SW & 2,50 & 14,00 & 2,50 & 777,85 & 49,09 & 15,94 & 712,83 & 3.742 \\
\hline Casa del Moro II & SW & $2,38^{*}$ & 14,25 & 2,50 & 805,58 & 44,30 & 16,33 & 744,95 & 3.911 \\
\hline El Teriñuelo & SW & 2,08 & 16,00 & 2,50 & $1.013,46$ & 33,82 & 18,70 & 960,94 & 5.045 \\
\hline La Torrecilla & SW & 4,75 & 16,25 & 3,00 & $1.258,47$ & 212,64 & 20,81 & $1.025,01$ & 5.381 \\
\hline Torrecilla & SW & 2,35 & 15,25 & 3,80 & $1.416,86$ & 65,93 & 26,74 & $1.324,19$ & 6.952 \\
\hline El Castillo & SW & 2,00 & 18,00 & 3,00 & $1.540,91$ & 37,70 & 25,50 & $1.477,71$ & 7.758 \\
\hline Vega de Olleros & SW & $3,46^{*}$ & 20,75 & 4,00 & $2.738,73$ & 150,29 & 38,04 & $2.550,40$ & 13.390 \\
\hline Santa Teresa I & SW & 2,40 & 20,75 & 4,00 & $2.738,73$ & 72,38 & 39,10 & $2.627,25$ & 13.793 \\
\hline Pedraza & SW & $4,17 *$ & 25,00 & 3,00 & $2.959,29$ & 163,62 & 34,38 & $2.761,30$ & 14.497 \\
\hline
\end{tabular}

*Cámaras cuyas dimensiones exactas desconocemos y que hemos calculado mediante la relación de un sexto respecto al túmulo. 


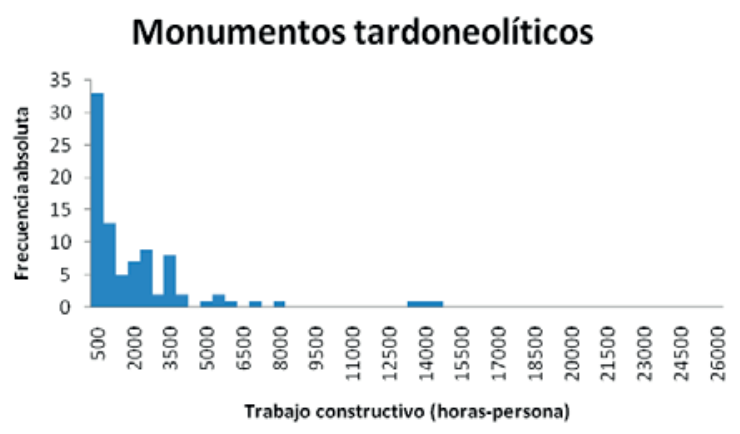

Figura 4. Histograma con la distribución del trabajo invertido en la construcción de los túmulos del Neolítico Final.

Considerando una altura de $2,5 \mathrm{~m}$ para la muralla de El Pedroso (podría haber sido incluso mayor), hemos realizado los cálculos que recogemos en la tabla 5, siendo el resultado de nuestra estimación de unos 6.000 días-persona para el poblado abulense y casi 46.000 días-persona invertidos en la construcción del zamorano.

En el caso de los recintos de fosos, vistas las distintas dimensiones que los de los lugares excavados ofrecen, así como la presencia de secciones en $\mathrm{V}$ o U, hemos optado por considerar una "sección tipo" ajustada a un trapezoide ideal de $3 \mathrm{~m}$ de anchura en la superficie, $1 \mathrm{~m}$ de anchura en la base y $2 \mathrm{~m}$ de profundidad. Para obtener el área del trapecio, "At", hemos empleado la siguiente fórmula, en la que "a" es la base mayor, "c" la base menor y "h" la altura:

$$
A t=\frac{a+c}{2} \cdot h
$$

Multiplicando el área de esta sección tipo por la longitud total de los anillos identificados mediante fotografía aérea y teledetección, la cual aparece descrita en

\section{Obras colectivas Calcolíticas. Recintos de fosos}

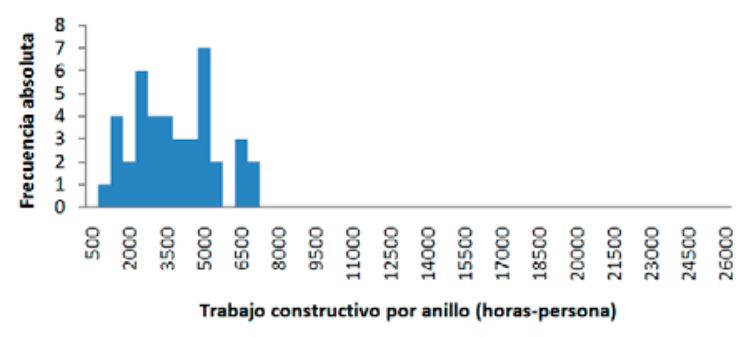
Obras colectivas calcolíticas. Recintos
de fosos

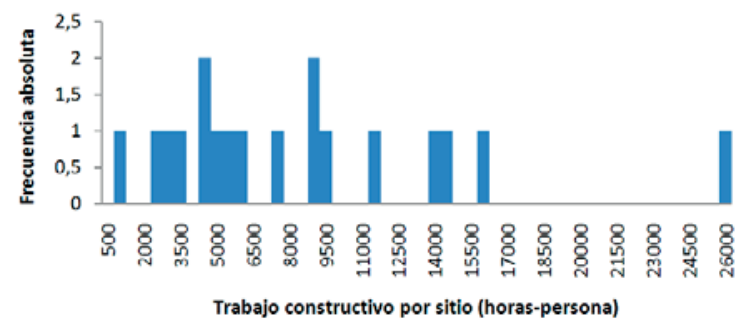

Figura 5. Histogramas con las distribuciones del trabajo invertido en la excavación de los anillos y de los recintos de fosos del Calcolítico.

Delibes y otros (2014), obtenemos el volumen de los fosos, que recogemos en la tabla 6 , en la que detallamos nuestros cálculos aplicando el coeficiente anteriormente descrito y recogemos los resultados por anillo y por yacimiento. Como se muestra en los histogramas de la figura 5, "en la mayor parte de los casos el trabajo dedicado a la excavación de los anillos se despliega entre los 1.000 y 5.000 días-persona y el total acumulado por cada asentamiento entre 4.000 y 12.000 días-persona, alcanzando algunos de ellos, como La Cuesta del Pájaro (Villeguillo, Segovia), un total de 26.000 días-persona.

Tabla 5. Cálculos realizados para estimar el trabajo dedicado a la construcción de los asentamientos amurallados del Calcolítico.

\begin{tabular}{|c|c|c|c|c|c|c|c|c|c|}
\hline \multirow{3}{*}{ Yacimiento } & \multicolumn{4}{|c|}{ Muralla } & \multicolumn{2}{|c|}{ Foso } & \multicolumn{3}{|c|}{ Trabajo (días-persona) } \\
\hline & \multicolumn{3}{|c|}{ Dimensiones (m) } & \multirow{2}{*}{$\begin{array}{l}\text { Volumen } \\
\qquad\left(\mathrm{m}^{3}\right)\end{array}$} & \multirow{2}{*}{$\begin{array}{c}\text { Sección } \\
\left(\mathrm{m}^{2}\right)\end{array}$} & \multirow{2}{*}{$\begin{array}{l}\text { Volumen } \\
\qquad\left(\mathrm{m}^{3}\right)\end{array}$} & \multirow{2}{*}{ Muralla } & \multirow{2}{*}{ Foso } & \multirow{2}{*}{ TOTAL } \\
\hline & Longitud & Espesor & Altura & & & & & & \\
\hline El Pedroso & 500 & 3,0 & 2,5 & 3750,00 & - & - & $45.937,50$ & - & $45.937,50$ \\
\hline Alto del Quemado & 137 & 1,5 & 1,5 & 308,25 & 3,56 & 487,72 & $3.776,06$ & $2.560,53$ & $6.336,59$ \\
\hline
\end{tabular}


Tabla 6. Cálculos realizados para estimar el trabajo dedicado a la construcción de los recintos fosados del Calcolítico.

\begin{tabular}{|c|c|c|c|c|c|}
\hline \multirow{2}{*}{ Nombre } & \multirow{2}{*}{ Foso } & \multirow{2}{*}{ Perímetro (m) } & \multirow{2}{*}{ Volumen $\left(\mathrm{m}^{3}\right)$} & \multicolumn{2}{|c|}{ Trabajo (días-persona) } \\
\hline & & & & Anillo & Total \\
\hline \multirow{5}{*}{ Cuesta del Pájaro } & 1 & 475 & 1.900 & 4.940 & \multirow{5}{*}{25.709} \\
\hline & 2 & 589 & 2.356 & 6.126 & \\
\hline & 3 & 374 & 1.496 & 3.890 & \\
\hline & 4 Int. & 433 & 1.732 & 4.503 & \\
\hline & 4 Ext. & 601 & 2.404 & 6.250 & \\
\hline \multirow{2}{*}{ El Campillo } & Int. & 473 & 1.892 & 4.919 & \multirow{2}{*}{11.253} \\
\hline & Ext. & 609 & 2.436 & 6.333 & \\
\hline \multirow{3}{*}{ Las Canteras } & Int. & 228 & 912 & 2.371 & \multirow{3}{*}{13.562} \\
\hline & Intrm. & 415 & 1.660 & 4.316 & \\
\hline & Ext. & 661 & 2.644 & 6.874 & \\
\hline \multirow{3}{*}{ El Casetón de la Era } & Int. & 150 & 600 & 1.560 & \multirow{3}{*}{9.360} \\
\hline & Intrm. & 262 & 1.048 & 2.725 & \\
\hline & Ext. & 488 & 1.952 & 5.075 & \\
\hline \multirow{2}{*}{ El Cesto III } & Int. & 141 & 564 & 1.466 & \multirow{2}{*}{5.002} \\
\hline & Ext. & 340 & 1.360 & 3.536 & \\
\hline \multirow{2}{*}{ La Corona } & Int. & 275 & 1.100 & 2.860 & \multirow{2}{*}{7.176} \\
\hline & Ext. & 415 & 1.660 & 4.316 & \\
\hline \multirow{3}{*}{ La Cuesta-Los Villares } & Int. & 231 & 924 & 2.402 & \multirow{3}{*}{14.144} \\
\hline & Intrm. & 460 & 1.840 & 4.784 & \\
\hline & Ext. & 669 & 2.676 & 6.958 & \\
\hline Las Ligeras de Abajo & 1 & 245 & 980 & 2.548 & 2.548 \\
\hline Los Melonaras-Zofraga & 1 & 319 & 1.276 & 3.318 & 3.318 \\
\hline \multirow{3}{*}{ El Mesón } & Int. & 162 & 648 & 1.685 & \multirow{3}{*}{8.715} \\
\hline & Intrm. & 226 & 904 & 2.350 & \\
\hline & Ext. & 450 & 1.800 & 4.680 & \\
\hline \multirow{2}{*}{ El Moscatel } & Int. & 214 & 856 & 2.226 & \multirow{2}{*}{5.824} \\
\hline & Ext. & 346 & 1.384 & 3.598 & \\
\hline El Parral & 1 & 439 & 1.756 & 4.566 & 4.566 \\
\hline \multirow{5}{*}{ Las Pozas } & 1 Int. & 198 & 792 & 2.059 & \multirow{5}{*}{15.600} \\
\hline & 1 Intrm. & 329 & 1.316 & 3.422 & \\
\hline & 1 Ext. & 444 & 1.776 & 4.618 & \\
\hline & 2 Int. & 202 & 808 & 2.101 & \\
\hline & 2 Ext. & 327 & 1.308 & 3.401 & \\
\hline
\end{tabular}




\begin{tabular}{|c|c|c|c|c|c|}
\hline \multirow{2}{*}{ Nombre } & \multirow{2}{*}{ Foso } & \multirow{2}{*}{ Perímetro (m) } & \multirow{2}{*}{ Volumen $\left(\mathrm{m}^{3}\right)$} & \multicolumn{2}{|c|}{ Trabajo (días-persona) } \\
\hline & & & & Anillo & Total \\
\hline San Martín-El Rasillo I & 1 & 90 & 360 & 936 & 936 \\
\hline San Miguel & 1 & 414 & 1.656 & 4.306 & 4.306 \\
\hline \multirow{2}{*}{ Santa Cruz } & Int. & 333 & 1.332 & 3.464 & \multirow{2}{*}{8.548} \\
\hline & Ext. & 489 & 1.956 & 5.086 & \\
\hline \multirow{2}{*}{ Santa Cruz III } & Int. & 144 & 576 & 1.498 & \multirow{2}{*}{4.118} \\
\hline & Ext. & 252 & 1.008 & 2.621 & \\
\hline \multirow{2}{*}{ Somante al Cuadro } & 1 & 120 & 480 & 1.248 & \multirow{2}{*}{2.392} \\
\hline & 2 & 110 & 440 & 1.144 & \\
\hline
\end{tabular}

\section{DISCUSIÓN}

Obviamente, para realizar una lectura humanista de estos datos debemos contextualizarlos en el trasfondo cultural que acogió la construcción de los monumentos. Como ya mencionamos en la introducción, los grupos prehistóricos que ocuparon la Meseta Norte vivieron una serie de cambios entre el Neolítico Antiguo y la Edad del Cobre que implicaron crecimiento demográfico, una mayor intensidad en la producción de determinados bienes y una más estrecha integración económica (Delibes de Castro y Fernández Manzano 2000, Villalobos García 2014a). Por tanto, puede afirmarse que, en función de la variable temporal, se aprecian ciertas transformaciones infraestructurales que, además, habrían conducido hacia una mayor complejidad social (Delibes de Castro et al. 1995, Guerra Doce et al. 2009, Rojo Guerra y Garrido Pena 2012). Así, consideramos perfectamente factible comparar estos procesos con la variable "trabajo invertido en monumentos" que hemos calculado.

Otra forma de contextualización la puede ofrecer la dimensión espacial. La Meseta Norte es un territorio que ocupa $95.000 \mathrm{~km}^{2}$ y que acoge distintas unidades morfoestructurales -valles, campiñas, penillanuras, montañas, etc. Aunque no pueda decirse que las prácticas subsistenciales difirieran significativamente en función de las distintas zonas del territorio, sí que se han identificado, no obstante, algunas singularidades culturales. Del Neolítico Final podemos citar el contraste entre las estrategias locacionales de los sepulcros megalíticos del noreste, en donde la mayor parte se yergue en zonas elevadas del terreno (Delibes de Castro et al. 1993, Moreno Gallo 2004), frente a los del suroeste, en su mayoría localizados en el fondo de los valles (Delibes de
Castro y Santonja Gómez 1986, Fabián García 1997), o también la existencia de un tipo arquitectónico particular, el redondil, en las campiñas centrales (Delibes de Castro 1995b). Para el Calcolítico se ha hablado de dos áreas distintas en función principalmente de las decoraciones cerámicas y de la presencia/ausencia de otros artefactos, que serían el Horizonte Las Pozas en el suroeste y el Horizonte Los Cercados en el noreste (Delibes de Castro y Val Recio 1990, Herrán Martínez et al. 1993: 38, Carmona Ballestero 2013: cap. 2.2), una distinción que, grosso modo, también es posible identificar en la distribución de los grupos de estilos decorativos del Campaniforme Ciempozuelos (Garrido Pena 2000: 139-142, Carmona Ballestero 2013: 36-39). Esto nos da pie para comparar si estas dos grandes áreas se corresponden también con alguna diferencia en cuanto a la variable "trabajo invertido en monumentos".

\subsection{Trabajo invertido en función del tiempo}

Una perspectiva con la que abordar los resultados de nuestras estimaciones es atendiendo a la evolución del trabajo invertido en monumentos a lo largo los tres periodos. Solo contamos con un caso de obra colectiva datada en el Neolítico Antiguo, aunque si de forma provisional tomamos al recinto de La Revilla y sus 216 días-persona como representativo, esto nos faculta para decir que en estos momentos el nivel de inversión en obras colectivas fue muy bajo. Con la eclosión del fenómeno megalítico en el Neolítico Final, apareció un conjunto de monumentos cuyos túmulos han supuesto en la mayor parte de los casos una dedicación de entre 250 y 2.500 días-persona aunque, como más adelante 


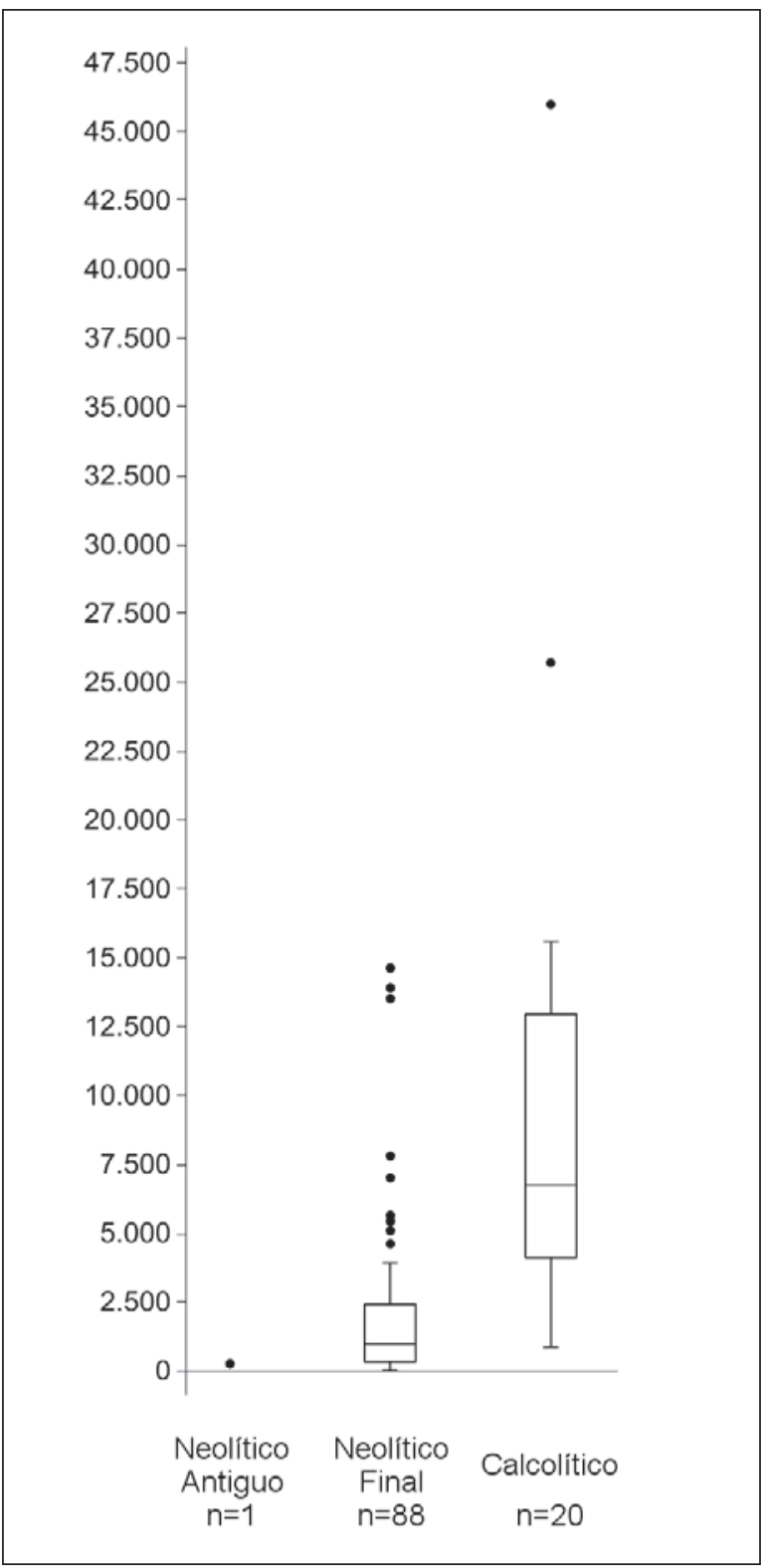

Figura 6. Diagramas de caja y bigotes con el trabajo total invertido por cada yacimiento en función de su época (días-persona).

explicaremos, en el suroeste normeseteño se erigieron algunos de estos de mayor envergadura, superando los 5.000 e, incluso, alcanzando los 15.000 días-persona. Por último, fue durante el Calcolítico cuando vemos el mayor despliegue de trabajo, con un conjunto de obras, ya sean recintos fosados o amurallados, los cuales supusieron entre 4.000 y 13.000 días-persona, y eso sin contar los casos excepcionales que alcanzaron 25.000 o, incluso, 46.000 días-persona.
Estos resultados dispuestos en forma de tres sucesivos diagramas de caja y bigotes, referentes a cada periodo temporal, son sumamente ilustrativos (fig. 6). En ellos se aprecia claramente que el trabajo destinado a las obras colectivas no solo aumentó con el tiempo sino que, además, lo hizo de forma exponencial. Si comparamos los conjuntos de trabajo dedicado a la construcción de los túmulos tardoneolíticos $(\mathrm{n}=88)$ y el dedicado a la construcción de los anillos calcolíticos $(\mathrm{n}=41)$ mediante una prueba $\mathrm{U}$ de Mann-Whitney - realizada con la herramienta "Mann-Whitney (two samples)" del software Past 2.17-, nos encontramos con que entre ambos existen diferencias estadísticamente significativas $(\mathrm{p}<0,01)$, al igual que sucede ( $\mathrm{p}$ $<0,01)$ si es entre el conjunto de túmulos de mayor envergadura, los del suroeste -ver infra- $(\mathrm{n}=43)$, con los anillos. Consideramos, por lo tanto, que estos datos son una sólida prueba para defender que en la Meseta Norte existió una tendencia firme y clara al aumento del trabajo destinado por obra monumental entre el Neolítico Antiguo y el Calcolítico.

\subsection{Trabajo invertido en función del territorio}

Obviamente, debido a que para el Neolítico Antiguo por el momento solo se conoce el excepcional caso del recinto de La Revilla, no es posible realizar una comparativa sincrónica de este momento. Sin embargo, para los túmulos del Neolítico Final contamos con un abundante contingente de datos de los sepulcros distribuidos por casi toda la Meseta. En cuanto al NMI necesarios para el acarreo de la laja mayor de cada monumento nos encontramos con que, si atendemos al coeficiente que implica más personal por unidad de masa transportada, en ninguno de los casos localizados en centro y noreste habrían requerido más de 80 personas pero que, por el contrario, son varios los megalitos del suroeste, como San Adrián (Granucillo, Zamora), Piedras Hincadas (Sanjuanejo, Salamanca), Casal del Gato (Almeida de Sayago, Zamora), el dolmen de Hondura (Hondura, Salamanca) y La Huerta de las Ánimas (Fuenteguinaldo, Salamanca), los que superan esta cifra hasta alcanzar los 163 individuos requeridos para el valor máximo, el de Los Castillos (La Hurtada, Salamanca). Si atendemos al total de días-persona para la construcción de los túmulos nos encontramos con un panorama similar, puesto que para el túmulo de mayor envergadura de todo el centro, este y noreste, que es el de Las Arnillas (Moradillo de Sedano, Burgos), hemos calculado unos 5.500 días-persona, cifra que superan los túmulos del 
sureste de La Torrecilla (San Benito de Valmuza, Salamanca), El Castillo (Castro Enríquez, Salamanca) o aquellos que incluso rebasan los 10.000 días-persona como Vega de Olleros (Carrascal del Obispo, Salamanca), Santa Teresa I (Robliza de Cojos, Salamanca) y, alcanzando el valor máximo de 14.500 días-persona, Pedraza (Castraz, Salamanca) (fig. 7).

Si realizamos una prueba U de Mann-Whitney a fin de comparar aquellos grupos comarcales que cuentan con una muestra de mayor tamaño, y que son los monumentos tardoneolíticos de los páramos palentinos y burgaleses del noreste de la Meseta Norte y los de las penillanuras salmantino-zamoranas del suroeste, nos encontramos con lo siguiente. En cuanto al NMI necesarios para el arrastre de las losas no existen diferencias estadísticamente significativas $(\mathrm{p}=0,15)$ entre los monumentos del noreste $(\mathrm{n}=13)$ y los del suroeste $(\mathrm{n}=34)$, pero al respecto de los días-persona requeridos para edificar los túmulos, estas sí que se constatan $(\mathrm{p}<$ $0,01)$ entre estos mismos grupos $(\mathrm{n}=37 \mathrm{y} \mathrm{n}=43$, respectivamente). Esto sugiere que, si bien las cuadrillas de trabajo no tuvieron necesariamente que ser diferentes para cada contexto, el hecho de que los túmulos de las penillanuras salmantino-zamoranas sean de mayor envergadura es algo que no obedece a la aleatoriedad.

Por último, en cuanto al periodo Calcolítico podemos comparar los dos tipos de obras colectivas conocidas, los poblados amurallados y los fosados, pues los primeros se ubican en la orla montañosa meridional y los segundos en la cuenca central (véase fig. 1). Como ya comentamos, para los recintos fosados hemos estimado entre los 2.500 y los 10.000 días-persona de trabajo total, en una distribución cuyo valor mediano es 6.500 días-persona. Esto ofrece una horquilla en la que el poblado amurallado de El Alto del Quemado, con sus particulares 6.337 días-persona, encuentra su perfecto acomodo. No hemos podido hacer el cálculo para los asentamientos amurallados de El Pozuelo y El Pico de la Mora, pero sus dimensiones, similares a las del poblado abulense -con muros circular de unos $30 \mathrm{~m}$ de diámetro el primero (Kunst y Rojo Guerra 1999) y recto durante unos $100 \mathrm{~m}$ el segundo (Rodríguez Marcos y Moral del Hoyo 2007, Rodríguez Marcos 2008)- nos permiten asumir para ellos, grosso modo, una cuantía de trabajo similar. Solo El Pedroso, con una muralla que habría requerido unos 46.000 díaspersona, supera holgadamente los 20.000 días-persona del mayor recinto conocido, La Cuesta del Pájaro. Por tanto, puede afirmarse que, exceptuando el caso de El Pedroso, los recintos de fosos del centro de la cuenca y los asentamientos amurallados de la periferia montañosa occidental y meridional de la Meseta Norte ocuparon una cantidad de trabajo similar.

Sin embargo, en cuanto a las obras colectivas calcolíticas no podemos hacer una comparativa norestesuroeste como sí que hicimos para el Neolítico Final, debido a que no se conocen recintos fosados ni lugares amurallados en toda la parte nororiental de la Meseta Norte. Se podría pensar que esto es debido a que este tipo de estructuras monumentales todavía no han sido identificadas en el registro arqueológico de esta zona, que se extendería por los dos tercios septentrionales del territorio de de las actuales provincias de $\mathrm{Pa}-$ lencia y Burgos, pero ya son muchas las intervenciones realizadas como para sostener esta hipótesis. Las excavaciones practicadas en lugares como los asentamientos domésticos de Doce Cantos (Herrera de Pisuerga, Palencia) (Pérez Rodríguez et al. 1990) o las amplias superficies interesadas en Fuente Celada (Quintanadueñas, Burgos), El Púlpito (Villalonquéjar, Burgos) y El Hornazo (Villimar, Burgos), con un total de 1.300, 2.300 y $10.000 \mathrm{~m}^{2}$ excavados respectivamente (Carmona Ballestero 2013: cap. 6.2), no han ofrecido estructuras similares. Solo en Rompizales I (Burgos), que también es un lugar doméstico calcolítico, se ha documentado una pequeña zanja en línea recta de $12 \mathrm{~m}$ de longitud y $65 \mathrm{~cm}$ de anchura (Carmona Ballestero 2013: 209 y fig. 137), cuyas dimensiones no la hacen equiparable a los grandes fosos circulares. Parece que las pruebas, de momento, indican que los recintos tuvieron su límite septentrional, aproximadamente, en los Montes Torozos.

Por lo tanto, puede decirse que, si atendemos a la dimensión espacial, tanto en el Neolítico Final como en el Calcolítico existe una diferencia en el trabajo invertido en las obras colectivas normeseteñas. Para el primer momento fueron los sepulcros suroccidentales los que implicaron una cantidad de trabajo significativamente mayor. En cuanto a la Edad del Cobre, podemos hablar de una marcada contraposición entre un suroeste-centro-sureste de asentamientos amurallados $\mathrm{y}$ fosados frente a un noreste carente de obras monumentales de cualquier tipo.

\section{CONCLUSIONES}

Esta aproximación nos ha permitido identificar un par de tendencias que creemos que pueden arrojar algo de luz al debate sobre la organización y las transformaciones sociales de la Prehistoria Reciente normeseteña, tanto en cuanto a la dimensión temporal como a la espacial. 


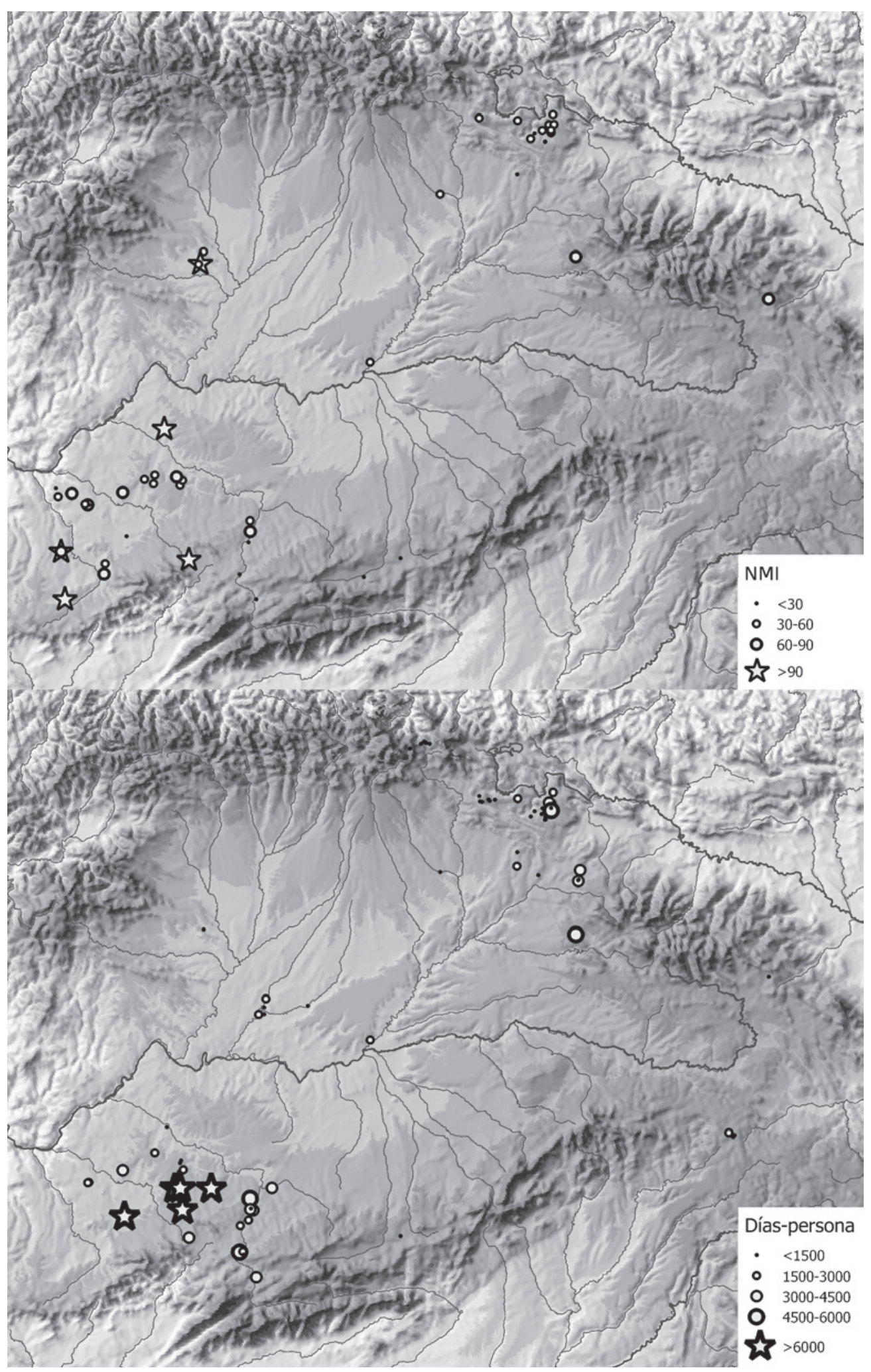

Figura 7. Mapas con la localización del NMI necesarios para el transporte del ortostato mayor y del trabajo invertido en la construcción de túmulos de los monumentos del Neolítico Final. 
La principal conclusión al respecto de la variable cronológica es el aumento aparentemente exponencial del trabajo invertido en cada conjunto monumental, lo cual podemos poner en relación con otros procesos conocidos. En la Meseta Norte se puede identificar un proceso de crecimiento demográfico sostenido (Delibes de Castro y Fernández Manzano 2000) que, aunque sea algo que por el momento todavía no se ha cuantificado con precisión, no tendría por qué desentonar con la progresión demográfica efectivamente exponencial que sí que se ha calculado que habría sucedido a escala peninsular (Balsera et al. 2015b). Sobre la economía de la Meseta Norte todavía sabemos poco del periodo intermedio que sería el Neolítico Final, pero podemos apuntar que con el paso del Neolítico al Calcolítico se produjo una intensificación de las prácticas agropecuarias (Delibes de Castro 2011) y aumentó la especialización de determinadas producciones como las de foliáceos de sílex (Val Recio y Herrán Martínez 1995), puntas de flecha de pizarra (Fábregas Valcarce y Rodríguez Rellán 2008), sal (Abarquero Moras et al. 2012) o adornos de variscita (Villalobos García y Odriozola, en prensa). En cuanto a los artefactos sociotécnicos, también es posible identificar un aumento claro en el número de colores empleado y en el trabajo dedicado su manufactura a lo largo de estas tres etapas cronoculturales (Villalobos García 2015). Todo esto, junto con la evolución del trabajo destinado a la construcción de monumentos, nos muestra que entre el Neolítico Antiguo y el Calcolítico la población aumentó y, con ella, la complejidad tanto de muchas de las actividades realizadas como de las interacciones y jerarquías interpersonales que habría sido necesario trenzar para su organización.

Pero si nos fijamos en la dimensión espacial, nos encontramos con que existe una clara distinción entre el trabajo que los grupos del área suroccidental y los del área nororiental destinaron a la construcción de monumentos, tanto en el Neolítico Final como en el Calcolítico. En el primero de los momentos se destinó una cantidad de trabajo significativamente mayor en los túmulos de las penillanuras suroccidentales que en los de los páramos nororientales. En el segundo vemos cómo la zona suroeste junto con la cuenca central y el extremo oriental acogieron lugares fosados y amurallados que, además de haber resultado más costosos que los túmulos del momento anterior, suponen un marcado contrapunto frente a un espacio nororiental totalmente carente de ellos.

Desde hace tiempo se han destacado las diferencias culturales entre el suroccidente y el nororiente normeseteño durante el Calcolítico (Herrán Martínez et al. 1993: 38), pero creemos que, además, hay pruebas suficientes como para defender que también existieron diferencias en cuanto a la organización social de uno y otro ámbito. En el espacio centro-suroccidental se conocen varias inhumaciones con ajuares conformados por abundantes artefactos sociotécnicos que incluyen armas de cobre y adornos de variscita (Delibes de Castro 1988, Fabián García 1995, Herrán Martínez y Rojo Guerra 1999), frente a un área nororiental caracterizado por unos ajuares siempre más modestos y monótonos (Arnáiz Alonso et al. 1997, Carmona Ballestero 2011, Delibes de Castro et al. 2012, Pérez-Romero et al. 2015). Es también la zona centro-suroccidental la que se halla inserta en un circuito suprarregional de intercambio de artefactos sociotécnicos como ídolos, adornos de marfil, cerámicas simbólicas o artefactos de caliza (Villalobos García 2013). Todavía queda por aclarar el comportamiento de estas variables en el extremo oriental de la Meseta Norte, pero debe apuntarse que en este lugar se dan tanto poblados amurallados - el caso antes citado de El Pozuelo- como la expresión de una considerable concentración de riqueza campaniforme, que incluye metalurgia, orfebrería y un vaso de origen posiblemente transpirenaico (Rojo Guerra et al. 2005, 2006, 2014). Por tanto, parece existir cierta correlación entre la presencia de artefactos exóticos, la exhibición de riqueza funeraria y una mayor cantidad de trabajo destinado a obras monumentales.

Vistas en conjunto, las dos tendencias -temporal y espacial- se muestran coherentes con el contexto cultural y socioeconómico conocido de la Meseta Norte, pues trabajo, demografía e intensificación económica corren paralelas a lo largo del tiempo, de igual manera a como sucede entre trabajo y desigualdad social en cuanto al espacio. Si consideramos la capacidad de movilizar y organizar el trabajo como un indicativo del tamaño del poder político, es posible identificar dos procesos históricos divergentes en este escenario. Por un lado, se encuentra el desarrollado en el centro-suroeste, donde a lo largo del Neolítico Final y el Calcolítico se habrían constituido unidades políticas cada vez más grandes, fuertes y con mayores desigualdades sociales internas. Por el otro, tenemos el del noreste, en el que a la aparición de poderes algo más débiles que los del suroeste durante el Neolítico Final le habría seguido su debilitamiento o disolución en el Calcolítico. En todo caso, creemos que este análisis sirve para demostrar que el cálculo del trabajo destinado a obras monumentales permite aportar una importante variable a tener en cuenta a la hora de abordar la poliédrica arqueología social de las culturas prehistóricas. 


\section{Agradecimientos}

El presente trabajo ha sido realizado durante la etapa predoctoral del autor, para cuyo desarrollo ha disfrutado de una ayuda para la formación de personal Investigador concedida por la Universidad de Valladolid.

\section{BIBLIOGRAFÍA}

Abarquero Moras, F. J.; Guerra Doce, E.; Delibes de Castro, G.; Palomino Lázaro, Á. L. y Val Recio, J. (2012): Arqueología de la Sal en las Lagunas de Villafáfila (Zamora): investigaciones sobre los cocederos prehistóricos. Valladolid, Junta de Castilla y León.

Arias González, L. (1989): “Contribución al estudio del Fenómeno Megalítico en el Occidente de la Meseta Norte: El dolmen de "El Torrejón" (Villarmayor, Salamanca)", en XIX Congreso Nacional de Arqueología. Vol. 1: 399-408. Zaragoza, Secretaría General de los Congresos Arqueológicos Nacionales.

Arnáiz Alonso, M. Á.; Pascual, S. y Rojo, A. V. (1997): "Los semejantes y los otros: La sepultura múltiple simultánea de Villayerno-Morquillas, Burgos. Nota preliminar". Boletín del Seminario de Estudios de Arte y Arqueología 63: 49-69.http://dialnet.unirioja.es/servlet/articulo? codigo $=67586$.

Balsera, V.; Bernabeu Aubán, J.; Costa Caramé, M. E.; Díaz del Río, P.; García Sanjuán, L. y Pardo, S. (2015a): "The radiocarbon chronology of Southern Spain's Late Prehistory (5600-1000 cal BCE): a comparative review". Oxford Journal of Archaeology 34 (2): 139-156. http://dx.doi.org 10.1111/ ojoa. 12053.

Balsera, V.; Díaz-del-Río, P.; Gilman, A.; Uriarte, A. y Vicent García, J. M. (2015b): “Approaching the demography of late prehistoric Iberia through summed calibrated date probability distributions (70002000 cal BC)". Quaternary International (in press). http://dx.doi.org/10.1016/j.quaint.2015.06.022.

Bernabeu Aubán, J.; Molina Balaguer, L.; Díez Castillo, A. y Orozco Köhler, T. (2006): "Inequalities and Power. Three millennia of Prehistory in Mediterranean Spain", en P. Díaz-del-Río y L. García Sanjuán (eds.), Social Inequality in Iberian Late Prehistory: 97-116. Oxford, Archaeopress.

Carmona Ballestero, E. (2011): "El registro funerario de Fuente Celada (Burgos): prácticas funerarias de las comunidades calcolíticas de la Meseta Norte".
Estrat Crític 5 (1): 502-507.http://dialnet.unirioja. es/servlet/articulo?codigo $=5010139$.

Carmona Ballestero, E. (2013): El Calcolítico en la Cuenca Media del Arlanzón (Burgos, España). Comunidades campesinas, procesos históricos y transformaciones. Oxford, Archaeopress.

Carmona Ballestero, E.; Arnaiz Alonso, M. Á. y Alameda Cuenca-Romero, M. C. (2014): "El dolmen de Arroyal I: usos y modificaciones durante el III milenio cal AC", en J. Honrado Castro, M. Á. Brezmes Escribano, A. Tejeiro Pizarro y Ó. Rodríguez Monterrubio (eds.), II Jornadas de Jóvenes Investigadores del Valle del Duero. Del Neolitico a la Antigüedad Tardía: 41-54. Valladolid, Glyphos Publicaciones.

Chapman, R. (2008): "Producing Inequalities: Regional Sequences in Later Prehistoric Southern Spain". Journal of World Prehistory 21 (3-4): 195-260. http://doi.org/10.1007/s10963-008-9014-y.

Childe, V. G. (1950): “The Urban Revolution". Town Planning Review 21 (1): 3-17. http://dx.doi. org/10.3828/tpr.21.1.k853061t614q42qh.

Delibes de Castro, G. (1988): "Enterramiento calcolítico en fosa de «El Ollar», Donhierro (Segovia)". Espacio, Tiempo y Forma. Prehistoria y Arqueología 1: 227-238.http://dialnet.unirioja.es/servlet/ articulo? codigo $=164745$.

Delibes de Castro, G. (1995a): "Neolítico y Edad del Bronce", en Historia de Zamora. Tomo I. De los Orígenes al final del Medievo: 47-100. Zamora, Instituto de Estudios Zamoranos Florián de Ocampo.

Delibes de Castro, G. (1995b): "Ritos funerarios, demografía y estructura social entre las comunidades neolíticas de la Submeseta Norte", en R. Fábregas Valcarce, F. Pérez Losada y C. Fernández Ibáñez (eds.), Arqueoloxía da Morte na Península Ibérica desde as Orixes ata o Medievo: 61-94. Xinzo de Limia,Exmo. Concello de Xinzode Limia.

Delibes de Castro, G. (2010): "La investigación de las sepulturas colectivas monumentales del IV milenio A.C. en la Submeseta Norte Española. Horizonte 2007”, en J. Fernández Eraso y J. A. Mújika Alustiza (eds.), Megalitismo y otras manifestaciones funerarias contemporáneas en su contexto social, económico y cultural: 12-56. San Sebastián, Aranzadi.

Delibes de Castro, G. (2011): El Pan y la Sal. La vida campesina en el Valle Medio del Duero hace cinco mil años. Valladolid, Real Academia de Bellas Artes de la Purísima Concepción.

Delibes de Castro, G.; Crespo Díez, M.; Fernández Manzano, J.; Herrán Martínez, J. I. y Rodríguez 
Marcos, J. A. (2009): “¿Stonehenge en Tierra de Campos? Excavaciones en el yacimiento de la Edad del Cobre de El Casetón de la Era (Villalba de los Alcores, Valladolid)", en E. Wattenberg (ed.), Conocer Valladolid. II Curso de Patrimonio Cultural: 15-33. Valladolid, Real Academia de Bellas Artes de la Purísima Concepción.

Delibes de Castro, G. y Fernández Manzano, J. (2000): "La trayectoria cultural de la Prehistoria Reciente (6400-2500 BP) en la Submeseta Norte: principales hitos de un proceso", en V. O. Jorge (ed.), Actas do $3 o$ Congresso de Arqueología Peninsular. Pré-Historia Recente da Península Ibérica: 95-112. Porto, Adecap.

Delibes de Castro, G.; García García, M.; Olmo Martín, J. y Santiago Pardo, J. (2014): Los recintos de fosos calcolíticos del valle medio del Duero: Arqueología Aérea y Espacial. Valladolid, Universidad de Valladolid.

Delibes de Castro, G.; Herrán Martínez, J. I.; Santiago Pardo, J. y Val Recio, J. (1995): "Evidence for Social Complexity in the Copper Age of the Northern Meseta", en K. T. Lillios (ed.), The Origins of Complex Societies in Late Prehistoric Iberia: 44-63. Ann Arbor (Michigan), International Monographs in Prehistory.

Delibes de Castro, G.; Moreno Gallo, M. Á.; Villalobos García, R.; y Basconcillos Arce, J. (2012): Piedra Alta. El guardián del tiempo. San Pedro Samuel (Burgos). Burgos, Diputación de Burgos.

Delibes de Castro, G. y Rojo Guerra, M. Á. (2002): "Reflexiones sobre el trasfondo cultural del polimorfismo megalítico en la Lora Burgalesa". Archivo Español de Arqueología 75: 21-35.http://doi. org/10.3989/aespa.2002.v75.126.

Delibes de Castro, G.; Rojo Guerra, M. Á. y Represa Bermejo, J. I. (1993): Dólmenes de La Lora. Burgos. Valladolid, Junta de Castilla y León.

Delibes de Castro, G. y Santonja Gómez, M. (1986): El fenómeno megalítico en la provincia de Salamanca. Salamanca, Diputación de Salamanca.

Delibes de Castro, G. y Val Recio, J. (1990): "Prehistoria reciente zamorana: del Megalitismo al Bronce", en I Congreso de Historia de Zamora. Vol. 2: 53 99. Zamora, Instituto de Estudios Zamoranos Florián de Ocampo.

Díaz-del-Río, P. (2003): "Recintos de fosos del III milenio AC en la Meseta peninsular". Trabajos de Prehistoria 60 (2): 61-78. http://dx.doi.org/10.3989/ tp.2003.v60.i2.81.

Earle, T. K. (1987): "Chiefdoms in archaeological and ethnohistorical perspective". Annual
Review of Anthropology 16: 279-308. http://dx.doi. org/10.1146/annurev.an.16.100187.001431.

Estremera Portela, M. S. y Fabián García, J. F. (2002): "El túmulo de la Dehesa de Río Fortes (Mironcillo, Ávila): Primera manifestación del Horizonte Rechaba en la Meseta Norte". Boletín del Seminario de Estudios de Arte y Arqueología 68: 9-41. http:// dialnet.unirioja.es/servlet/articulo? codigo $=856493$.

Fabián García, J. F. (1995): El aspecto funerario durante el Calcolítico y los inicios de la Edad del Bronce en la Meseta Norte. Salamanca, Universidad de Salamanca.

Fabián García, J. F. (1997): El dolmen del Prado de las Cruces (Bernuy-Salinero, Ávila). Valladolid, Junta de Castilla y León.

Fábregas Valcarce, R. y Rodríguez Rellán, C. (2008): "Gestión del cuarzo y la pizarra en el Calcolítico peninsular: El "santuario" de El Pedroso (Trabazos de Aliste, Zamora)". Trabajos de Prehistoria 65 (1): 125-142. http://dx.doi.org/10.3989/tp.2008. v65.i1.139.

Fernández Eraso, J., y Mújika Alustiza, J. A. (2010): Megalitismo y otras manifestaciones funerarias contemporáneas en su contexto social, económico y cultural. San Sebastián, Aranzadi.

García García, M. (2013): “Las Pozas (Casaseca de las Chanas, Zamora): dos nuevos recintos de fosos calcolíticos en el Valle del Duero". Trabajos de Prehistoria 70 (1): 175-184. http://doi.org/10.3989/ tp.2013.12108.

Garrido Pena, R. (2000): El Campaniforme en La Meseta Central de la Península Ibérica (c. 2500-2000 $A C$.). Oxford, Archaeopress.

Gibaja Bao, J. F.; Crespo Díez, M.; Delibes de Castro, G.; Fernández Manzano, J.; Fraile Márquez, C.; Herrán Martínez, J. I.; Palomo, J. I. y Rodríguez Marcos, J. A. (2012): "El uso de trillos durante la Edad del Cobre en la Meseta española. Análisis traceológico de una colección de denticulados de sílex procedentes del "recinto de fosos" de El Casetón de la Era (Villalba de los Alcores, Valladolid)". Trabajos de Prehistoria 69 (1): 133-148. http://doi. org/10.3989/tp.2012.12084.

González López, M. A. y Teijeiro López, B. (1997): "Trabajo y demografía en el III milenio: el paisaje megalítico en el occidente de la Meseta Norte", en XXIV Congreso Nacional de Arqueología. El mundo indígena: 131-142. Murcia, Instituto de Patrimonio Histórico.

Guerra Doce, E.; Delibes de Castro, G.; Zapatero Magdaleno, P. y Villalobos García, R. (2009): "Primus 
Inter Pares: estrategias de diferenciación social en los sepulcros megalíticos de la Meseta Norte Española”. BSAA Arqueología 75: 41-65. http://dialnet. unirioja.es/servlet/articulo?codigo $=3627354$.

Herrán Martínez, J. I.; Iglesias Martínez, J. C. y Palomino Lázaro, Á. L. (1993): "Intervención arqueológica de urgencia en el yacimiento de la Edad del Cobre de Santa Cruz (Roa de Duero, Burgos)". Nvmantia 4: 27-40.

Herrán Martínez, J. I. y Rojo Guerra, M. Á. (1999): “¿Una nueva tumba en fosa calcolítica?: el hallazgo de Colmenares (Portillo, Valladolid, España) y su contexto arqueológico". Estudos Pré-Históricos 7: 111-124.

Jorge, S. O. (1994): “Colónias, Fortificações, Lugares Monumentalizados. Trajectória das Concepções sobre um tema do Calcolítico Peninsular". Revista da Faculdade de Letras. Porto. História. II Série 11: 447-546. http://dialnet.unirioja.es/servlet/ articulo? codigo $=2338013$.

Kolb, M. J. (1997): “Labor mobilization, ethnohistory, and the archaeology of community in Hawai'i". Journal of Archaeological Method and Theory 4 (3): 265-285. http://doi.org/10.1007/BF02428064.

Kunst, M., y Rojo Guerra, M. Á. (1999): “El Valle de Ambrona: un ejemplo de la primera colonización Neolítica de las tierras del Interior Peninsular", en J. Bernabeu Aubán y T. Orozco Köhler (eds.), II Congrés del Neolític a la Península Ibérica: 259-270. Valencia, Universidad de Valencia.

López Plaza, S. (1982): Aspectos arquitectónicos de los sepulcros megalíticos de las provincias de $\mathrm{Sa}$ lamanca y Zamora. Salamanca, Universidad de Salamanca.

López Plaza, S. (1994): "El Alto del Quemado, poblado calcolítico fortificado en el SO de la Meseta Norte Española". Trabalhos de Arqueología da EAM 2: 201-214.

Márquez Romero, J. E., y Jiménez Jáimez, V. J. (2010): Recintos de Fosos. Genealogía y significado de una tradición en la Prehistoria del suroeste de la Península Ibérica (IV-III milenios AC). Málaga, Universidad de Málaga.

Moreno Gallo, M. Á. (2004): Megalitismo y geografia. Análisis de los factores de localización espacial de los Dólmenes de la provincia de Burgos. Valladolid, Universidad de Valladolid.

Moreno Gallo, M. Á. (2009): “Apuntes para un inventario del megalitismo en el norte de la provincia de Palencia". BSAA Arqueología 75: 67-89. http://dialnet.unirioja.es/servlet/articulo?codigo $=3627359$.
Muñoz Carballo, G. (1986): Actas de la Mesa Redonda sobre Megalitismo Peninsular. Madrid, Asociación Española de Amigos de la Arqueología.

Palomino Lázaro, Á. L. (1989): "Las manifestaciones tumulares no megalíticas del centro de la Meseta. Nuevas aportaciones de la provincia de Zamora". Anuario del Instituto de Estudios Zamoranos Florián de Ocampo 1989: 181-189.

Palomino Lázaro, Á. L. (1990): "Nuevas aportaciones al conocimiento del fenómeno megalítico de la provincia de Zamora", en I Congreso de Historia de Zamora. Vol. 2: 173-200. Zamora, Instituto de Estudios Zamoranos Florián de Ocampo.

Palomino Lázaro, Á. L.; Delibes de Castro, G.; Rojo Guerra, M. Á.; Abarquero Moras, F. J.; Moreno Gallo, M. Á. y Negredo García, M. J. (2006): “El Turrumbero de la Cañada, Arquitectura megalítica al pie de la Sierra de Atapuerca", en N. Bicho (ed.), Simbolismo, arte e espaços sagrados na pré-historia da Península Ibérica: Actas do IV Congresso de Arqueologia Peninsular: 143-155. Faro, Universidade do Algarve.

Palomino Lázaro, Á. L., y Rojo Guerra, M. Á. (1997): "Un nuevo yacimiento neolítico de habitación infratumular: "El Teso del Oro", en San Martín de Valderaduey (Zamora)", en R. Balbín y P. Bueno (eds.), II Congreso de Arqueología Peninsular. Neolítico, Calcolítico y Bronce: 249-256. Zamora, Fundación Rei Afonso Henriques.

Pérez Rodríguez, F. J. (2010): “El fenómeno megalítico en la Montaña Palentina". Colección de Historia Montaña Palentina 4: 11-64.

Pérez Rodríguez, F. J.; Fernández Gutiérrez, J. M. y Puertas Gutiérrez, F. (1990): “Los Doce Cantos (Herrera de Pisuerga). Un yacimiento calcolítico precampaniforme en el norte de la provincia de $\mathrm{Pa}-$ lencia", en Actas del II Congreso de Historia de Palencia. Vol. 1: 95-109. Palencia, Diputación de Palencia.

Pérez-Romero, A.; Iriarte, E.; Galindo-Pellicena, M. Á.; García-González, R.; Rodríguez, L.; Castilla, M.; Francés-Negro, M.; Santos, E.; Valdiosera, C.; Arsuaga, J. L.; Alday Ruiz, A. y Carretero Díaz, J. M. (2015): "An unusual Pre-bell beaker Copper Age cave burial context from El Portalón de Cueva Mayor site (Sierra de Atapuerca, Burgos)". Quaternary International, in press. http://dx.doi.org/10.1016/j. quaint.2015.06.063.

Peterson, C. E., y Drennan, R. D. (2012): "Patterned variation in regional trajectories of community growth", en M. E. Smith (ed.), The Comparative 
Archaeology of Complex Societies: 88-137. New York, Cambridge University Press.

Renfrew, C. (1973): "Monuments, mobilization and social organization in Neolithic Wessex", en C. Renfrew (ed.), The Explanation of Culture Change. Models in Prehistory: 539-558. Gloucester, Duckworth.

Rodríguez Marcos, J. A. (2008): Estudio secuencial de la Edad del Bronce en la Ribera del Duero (provincia de Valladolid). Valladolid, Junta de Castilla y León.

Rodríguez Marcos, J. A. y Moral del Hoyo, S. (2007): "Algunas notas acerca del poblamiento campaniforme en el sector vallisoletano de la Ribera del Duero". Zephyrus 60: 181-194. http://revistas.usal. es/index.php/0514-7336/article/view/5577.

Rojo Guerra, M. Á. (1992): El fenómeno megalítico en la Lora burgalesa. Tesis Doctoral, Universidad de Valladolid. Inédita.

Rojo Guerra, M. Á. y Garrido Pena, R. (2012): “Frompits to megaliths: neolithic burials in the interior of Iberia", en J. F. Gibaja, A. F. Carvalho, y P. Chambon (eds.), Funerary Practices in the Iberian Peninsula from the Mesolithic to the Chalcolithic: 2128. Oxford, Archaeopress.

Rojo Guerra, M. Á.; Garrido Pena, R. y García Martínez de Lagrán, Í. (2006): "Un peculiar vaso campaniforme de estilo marítimo del túmulo de La Sima, Miño de Medinaceli (Soria, España): reflexiones en torno a las técnicas decorativas campaniformes y los sistemas de intercambios a larga distancia”. Trabajos de Prehistoria 63: 133-147. http://doi. org/10.3989/tp.2006.v63.i1.8.

Rojo Guerra, M. Á.; Garrido Pena, R. y García Martínez de Lagrán, Í. (2008a): "Everyday routines or special ritual events? Bell Beakers in domestic contexts of Inner Iberia”, en M. Baioni, V. Leonini, D. LoVetro, F. Martini, R. Poggiani y L. Sarti (eds.), Bell Beaker in Everyday Life: 321-326. Firenze, Museo Fiorentino di Preistoria Paolo Graziosi.

Rojo Guerra, M. Á.; Garrido Pena, R.; García Martínez de Lagrán, Í. y Kunst, M. (2008b): “Los recintos del poblado del Neolítico Antiguo de La Revilla del Campo (Ambrona, Soria)", en M. S. Hernández Pérez, J. A. Soler Díaz y J. A. López Padilla (eds.), IV Congreso del Neolítico Peninsular. Vol. 1: 252-258. Alicante, Museo Arqueológico de Alicante.

Rojo Guerra, M. Á., Garrido Pena, R., García Martínez de Lagrán, Í., y Tejedor Rodríguez, C. (2014). "Beaker barrows (not) for the dead: El Alto I \&
III, Las Cuevas/El Morrón and La Perica (Soria, Spain)". Cuadernos de Prehistoria y Arqueología Universidad Autónoma de Madrid 40: 31-40. http:// www.uam.es/otros/cupauam/pdf/Cupauam40/resum4002.htm.

Rojo Guerra, M. Á.; Garrido Pena, R.; Morán Dauchez, G.; García Martínez de Lagrán, Í. y Kunst, M. (2005): "Del enterramiento colectivo a la tumba individual: el sepulcro monumental de La Sima en Miño de Medinaceli, Soria, España”. BSAA Arqueología 71: 11-42. http://dialnet.unirioja.es/servlet/ articulo?codigo $=2303046$.

Rojo Guerra, M. Á.; Kunst, M.; Garrido Pena, R.; García Martínez de Lagrán, Í. y Morán Dauchez, G. (2005): Un desafio a la eternidad: Tumbas monumentales del Valle de Ambrona. Valladolid, Junta de Castilla y León.

Rojo Guerra, M. Á.; Kunst, M.; Garrido Pena, R.; García Martínez de Lagrán, Í. y Morán Dauchez, G. (2008c): Paisajes de la Memoria: Asentamientos del Neolítico Antiguo en el Valle de Ambrona (Soria, España). Valladolid, Universidad de Valladolid. Siegesmund, S. y Snethlage, R. (2011): Stone in Architecture. Properties, durability (4th edition). Berlín, Springer-Verlag.

Tejedor Rodríguez, C. (2014): "Reconstruyendo "biografías megalíticas": algunos ejemplos de alteraciones estructurales en monumentos megalíticos del valle del Duero/Douro", en J. Honrado Castro, M. Á. Brezmes Escribano, A. Tejeiro Pizarro y Ó. Rodríguez Monterrubio (eds.), II Jornadas de Jóvenes Investigadores del Valle del Duero. Del Neolítico a la Antigüedad Tardia: 67-86. Valladolid, Glyphos Publicaciones.

Trigger, B. G. (1990): "Monumental architecture: a thermodynamic explanation of human behaviour". World Archaeology 22 (2): 119-132. http://doi.org/1 0.1080/00438243.1990.9980135.

Val Recio, J. y Herrán Martínez, J. I. (1995): “El Calcolítico precampaniforme en el Duero Medio", en M. Kunst (ed.), Origens, Estruturas e Relações das Culturas Calcolíticas da Península Ibérica: 293354. Torres Vedras, Instituto Português de Património Arquitectónico e Arqueológico.

Vázquez Varela, J. M.; Criado Boado, F. y Bello Diéguez, J. M. (1987): La cultura megalítica de la provincia de La Coruña y sus relaciones con el marco natural: implicaciones socio-económicas. La Coruña, Diputación Provincial de La Coruña.

Villalobos García, R. (2013): “Artefactos singulares de filiación meridional en el Calcolítico de la Meseta Norte Española: un vaso calcáreo procedente de El 
Fonsario (Villafáfila, Zamora)". Zephyrus 71: 131148. http://revistas.usal.es/index.php/0514-7336/ article/view/9960.

Villalobos García, R. (2014a): "La trayectoria historiográfica de los inicios de la Prehistoria Reciente (VI a III milenios cal AC) en la Meseta Norte Española", en J. Honrado Castro, M. Á. Brezmes Escribano, A. Tejeiro Pizarro y Ó. Rodríguez Monterrubio (eds.), II Jornadas de Jóvenes Investigadores del Valle del Duero. Del Neolitico a la Antigüedad Tardía: 17-31. Valladolid, Glyphos Publicaciones.

Villalobos García, R. (2014b): "The megalithic tombs of the Spanish Northern Meseta. Material, political and ideological ties between the Neolithic people and their territory". Préhistoires Méditerranéennes Colloque 2014 Préhistoire Méditerranéenne. http:// pm.revues.org/1047.
Villalobos García, R. (2015): "Evolución de los sistemas de artefactos socioténicos empleados en la Meseta Norte Española durante el Neolítico y Calcolítico", en A. Cruz y E. Cerrillo Cuenca (eds.), $2^{a}$ Mesa-redonda Peninsular Tráfego de Objetos, Tráfego Tecnológico: síntomas das ideologias dominantes na Ibéria. Para-Actas: 25-32. Tomar, Centro de Pré-História do Instituto Politécnico de Tomar. http://www.cph.ipt.pt/download/AntropeDownload/Para-Actas\%201.pdf.

Villalobos García, R. y Odriozola, C. P. (en prensa): "The Organisation of Variscite Personal Ornament Production during Late Prehistory in the Iberian Peninsula: The Mines of Aliste and the Production Sites of Quiruelas de Vidriales (Zamora, Spain)". European Journal of Archaeology: aceptado-en prensa. 